\title{
EFFECTS OF SUSPENDED MULTI-WALLED CARBON NANOTUBES ON \\ DAPHNID GROWTH AND REPRODUCTION
}

Matthew Michael Alloy, B. A.

Thesis Prepared for the Degree of

MASTER OF SCIENCE

UNIVERSITY OF NORTH TEXAS

May 2010

APPROVED:

Aaron P. Roberts, Major Professor

Barney Venables, Committee Member and Program Coordinator

Duane Huggett, Committee Member Stephen J. Klaine, Committee Member

Arthur J. Goven, Chair of the Department of Biological Sciences

Michael Monticino, Dean of the Robert B.

Toulouse School of Graduate Studies 
Alloy, Matthew Michael. Effects of suspended multi-walled carbon nanotubes on Daphnid growth and reproduction. Master of Science (Environmental Science), May 2010, 56 pp., 7 tables, 17 illustrations, references, 79 titles.

Multi-walled carbon nanotube aggregates can be suspended in the aqueous phase by natural organic matter. These aggregates are ingested by filter feeding zooplankton. Ingested aggregates result in decreased growth and decreased reproduction. These effects may be caused by reduction in energy input from normal feeding behavior.

$\mathrm{pH}$ alters natural organic matter structure through changes in electrostatic repulsion. Altered natural organic matter structure changes multi-walled carbon nanotube aggregate size. This size variation with variation in $\mathrm{pH}$ is significant, but not large enough a change in size to alter toxicity, as the aggregate size range remains well within the particle size selection of the organisms. 
Copyright 2010

by

Matthew Michael Alloy 


\section{ACKNOWLEDGEMNTS}

I would like to thank my entire committee, Dr. Barney Venables, Dr. Duane Huggett, Dr. Stephen Klaine, and my major advisor, Dr. Aaron Roberts. I would also like to thank some of the people who made my work possible: Aaron Edgington, Dr. Nandika D'Souza, Benjamin Barst, and Charles Mansfield. For supporting me, even when my research kept me away from them, I would like to thank my parents. This work was supported by US EPA STAR Grant R834092. 
TABLE OF CONTENTS

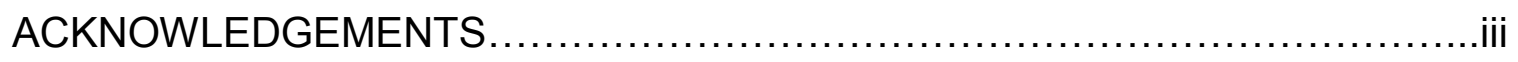

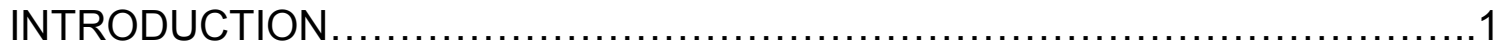

Carbon Nanotubes

Toxicity

Carbon Nanotubes in Aquatic Ecosystems

GOALS AND HYPOTHESES ......................................................

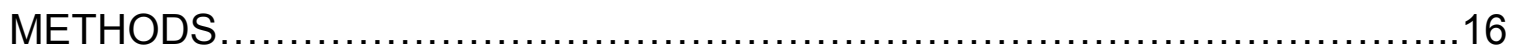

Material Preparation

Material Characterization

Test Organisms

Bioassays

Data Analysis

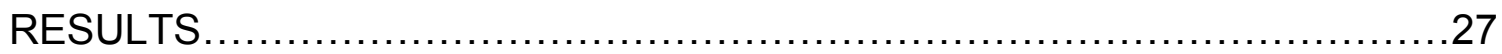

Material Characteristics

Survival

Growth

Reproduction

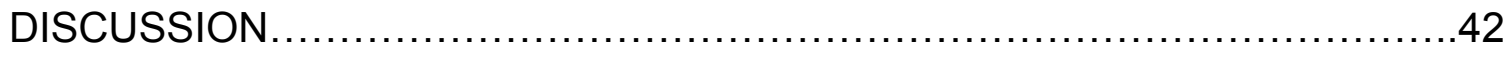

Survival

Growth 
Effect of $\mathrm{pH}$ on Growth and Survival

Reproduction

Conclusions

Future Directions

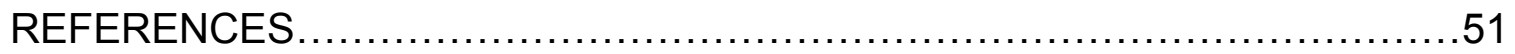




\section{INTRODUCTION}

\section{Carbon Nanotubes}

The US National Nanotechnology Initiative (NNI) defines nanoparticle as any particle that has at least one dimension within the range of 1 nanometer to 100 nanometers (Russell et al. 2000). Carbon nanotubes (CNT) are hollow nanoscale tube structures composed of carbon rings with very strong $\mathrm{sp}^{2}$ bonds. Although the first description of "graphitic carbon fibers" was by two Russian scientists (Radushkevich and Lukyanovich 1952), it is mostly due to timing and new resolutions in transmission electron microscopy (TEM) imaging, credit for the discovery of CNTs has most commonly been given to Sumio lijima (lijima 1991). CNTs are relatively new to materials science and the full breadth of their application is still in early development.

CNTs are divided into two categories: single-walled (SWNT) and multiwalled (MWNT). The former varies by diameter, length and chirality. The latter consists of smaller diameter single-walled tubes inside larger diameter tubes and may vary from a double-walled nanotube to as many as fifty concentric tubes (Yamabe 1995). The interwall space between concentric tubes is $0.34 \mathrm{~nm}$ (Ajayan 1999).

Single and multi-walled nanotubes have a large amount of surface area in relation to mass. All chemical interaction occurs on this surface, giving CNTs a 
great deal of potential for bonding and reaction (Helland et al. 2007, Oberdörster et al. 2005).

CNTs are classified as artificial materials even though they can be produced by natural processes, including volcanic events (Velasco-Santos et al. 2003). CNTs have been found in ice core samples (Esquivel and Murr, 2004), deep rock formations, and crude oil in ultra-trace concentrations (Velasco-Santos et al. 2003). CNTs also form in less extreme conditions such as incinerators (Murr et al. 2004, 2005). However, the size, purity, quality, and quantity of CNTs produced by such processes are far below what is needed for laboratory testing or composite material applications. For the foreseeable future, the only major source of CNTs is laboratory and industrial production. The annual SWNT production, as of 2004, was $9,000 \mathrm{~kg} / \mathrm{yr}$ (Templeton et al. 2006). A single German company, Bayer, increased MWNT production capacity to 60 metric tons per year in 2007 (Rakov 2008). The same company announced plans to increase further to 200 tons per year by 2009 and 3,000 tons per year by 2012 (Rakov 2008).

Diameters of CNTs range from one to several nanometers, while lengths in excess of one centimeter have been achieved (Hyung 2008). Depending on the diameter and chirality, the tubes may have electrochemical properties similar to metals (Ouyang et al. 2001), or as semiconductors (Itkis et al. 2002). Their variability in electrochemical behavior makes them attractive to microelectronic applications (Avouris 2007). Single-walled nanotubes (SWNTs) have already 
been used in microtransistors and experimental processor architecture (Derycke 2001, 2009). Others have proposed using CNTs in medicine as carrier-mediated delivery vehicles for biofunctional molecules, as targets for biophysical treatments, and as templates for tissue regeneration (Foldvari and Bagonluri, 2008). Electronic circuits could be scaled down by several orders of magnitude by using conductive CNTs in the place of traditional conductive materials. SWNTs have already been used as field effect transistors (Dercyke et al. 2001). MWNTs are viewed as attractive new materials for processor architecture beyond the $22 \mathrm{~nm}$ node (Naeemi et al. 2005). A ring oscillator using a single SWNT was tested in 2005 (Chen et al. 2006). Applications for CNTs range from integration into bulk materials, to circuits measuring less than $90 \mu \mathrm{m}^{2}$. Material engineers have designed composite materials using CNTs with many times the strength and durability, yet a fraction of the weight and stiffness of current materials. The proposed uses of CNTs range from domestic to military applications. Military applications include sorbative filters, use as visual obscurants on the battlefield, simple paints, and hybrid polymer structural materials for vehicles and buildings (Kennedy et al. 2008).

In 2005, worldwide funding for nanotechnology was estimated to be 9.6 billion USD (Lux Research Inc. 2006). Projections of the nanomaterials industry reach as high as 1 trillion USD by 2015 (Nel et al. 2006). These projections reflect a wide range of industrial sources of CNTs, and widespread CNT use. 
This supposition of widespread manufacture and use of CNTs presents a variety of environmental routes of exposure, as both large quantities of CNTs will be used in mass production of bulk composite materials, and very small quantities will be used in microprocessor architecture, but with a potential to be as ubiquitous as cell phones and notebook computers. Potential widespread use of CNT composites may lead to an unavoidable pervasiveness of CNTs in postconsumer waste streams (Figure 1).

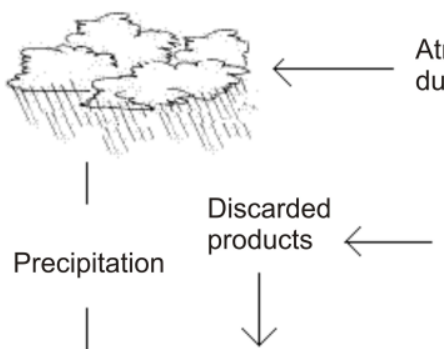

Atmospheric suspension during manufacture

Carbon nanotubes to the consumer
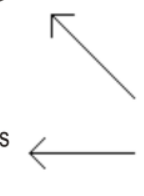<smiles>C1CCCCC1</smiles>

Industrial Effluent<smiles>C=CC(C)(C)C</smiles>
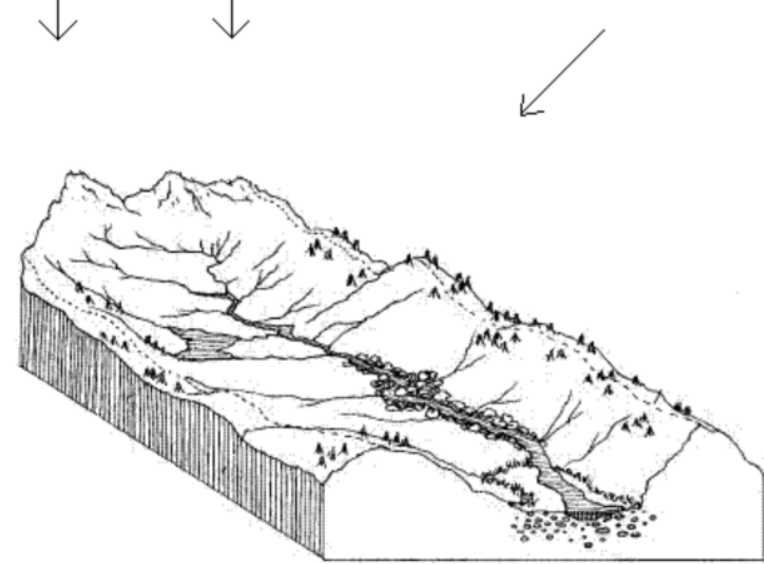

Fig. 1. Expected routes of carbon nanotube release into aquatic systems. (Figure from US EPA http://epa.gov/watershed/what.html). 


\section{Toxicity}

The toxicity of CNTs includes macro-level effects on organisms, such as granuloma formation in alveoli in lungs of Cavia porcellus (Grubek-Jaworska et al. 2006). The authors conducted inhalation studies and reported that CNT aggregates often become too large to pass directly through the alveolar walls, and instead build up and block alveolar space. The same study showed a litany of lung pathologies associated with MWNTs from a variety of purities and origins. Pathologies included: perivascular, peribronchial and interstitial infiltration of inflammatory cells, central and peripheral atelectasis (lung collapse) and emphysema (destruction of alveolar support structures) and alveolar exudation (oozing fluid). Smith et al. (2007) reported increasing gill mucous and dose dependent decrease of glutathione in the liver of Oncorhynchus mykiss. Tu et al. (2009) showed DNA sequences selectively binding to SWNTs in vitro, though the ability of CNTs to enter cells and their nucli have not been substantially supported in the literature.

Much of the toxicological study of CNTs has centered on airborne aggregates. This has been driven by the need for data to ensure occupational safety for those involved in the manufacture of CNTs and other nanomaterials. Maynard et al. (2004) studied CNT deposits on protective gloves used by workers producing and processing the nanomaterials. They found that even careful handling still resulted in both the release of aggregates into the air (less than $53 \mu \mathrm{g} / \mathrm{m}^{3}$ ), which stayed suspended for prolonged periods of time (as long 
as $1 \mathrm{hr} 30 \mathrm{~min}$ ), and deposits on gloves ranging from $0.2 \mathrm{mg}$ per hand to $6.0 \mathrm{mg}$ per hand (Maynard et al. 2004).

Studies have been done on the lungs in rodents as well as lung cell lines.

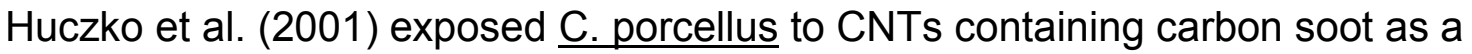
preliminary study seeking to emulate workplace exposure occurring during refining and purification of CNTs. The authors did not find any significant differences in intertidal volume, respiration rates, and resistance to tidal flow between the CNTs and soot exposures and soot without CNTs controls. Neither did the authors find any significant differences among treatments in bronchoalveolar lavage examinations of macrophage counts, total protein, polymorphonulcear leukocytes, lymphocytes, or losinophils (sic) (Huczko et al. 2001). Shvedova et al. (2005) exposed mice to CNTs through pharyngeal aspiration. They observed that within the first three days there was a dosedependent increase in protein, lactate dehydrogenase, and glutamyl transferase activities in bronchoalveolar tissues, as well as a depletion of glutathione. By day three, they observed lymphocyte influx. Proinflammatory cytokines were seen to increase from day one and peak on day seven. The primary morphologies observed were hypertrophied epithelial cells surrounding SWNT aggregates and diffuse interstitial fibrosis with alveolar wall thickening (Shvedova et al. 2005). Intratracheal instillation into rats showed temporary inflammation and multifocal granulomas around SWNT aggregates (Warheit et al. 2004). Lam et al. (2004) observed epitheliod granuloma lesions after a single instillation into mice. 
There is some question as to the method of instillation used being the cause of the granulomas rather than the CNTs themselves (Helland et al. 2007). Monteiro-Riviere et al. (2005) observed well dispersed MWNTs were able to enter cultured human epidermal keratinocytes and elicit an inflammatory response. They reported MWNTs alter protein Interleukin-8 release in keratinocytes. Huczko and Lange (2001) exposed the skins of forty human volunteers to fullerene soot containing CNTs in an in vivo patch test, and four albino rabbits were subjected to eye exposure. The authors reported no significant response and concluded that dermal exposure to CNTs is not associated with any risks.

Few studies can be found in the literature examining CNT toxicity to aquatic biota. Roberts et al. (2007) observed that lipid coated carbon nanomaterials may not be highly stable in aquatic environments due to biotic interactions. The authors reported that zooplankton ( $\underline{\text { D. magna) }}$ ) not only ingested CNT aggregates from the water column, also but altered the lipid coating. Toxicity was observed only at very high concentrations. Other investigators have observed ingestion of suspended MWNT aggregates in a fine-mesh filter feeder organism, Ceriodaphnia dubia (Kennedy et al. 2008).

Fullerenes, another carbon nanomaterials, have been shown to interact differently with biota depending on surface functionalization. Suspended $\mathrm{C}_{60}$ fullerenes have been reported to induce lipid peroxidation in the brains of juvenile bass (Micropterus salmoides) (Oberdörster, 2004). However, others have 
reported that interactions between the CNTs and assay reagents are responsible for false positives (Worle-Knirsch et al. 2006), or that metal catalyst impurities are the cause of confirmed reactive oxygen species generation (Pulskamp et al. 2006). The solvent tetrahydrofuran (THF) has been used to solubilize $\mathrm{C}_{60}$ in bioassays (Zhu et al. 2006, Oberdörster, 2004). It has been reported that toxic endpoints observed in many of those assays could be attributed to THF decomposition products (Henry et al. 2007). In their D. magna bioassays with nanoparticulate $\mathrm{TiO}_{2}$ and $\mathrm{C}_{60}$, Lovern and Klaper (2006) used THF, but constructed their method to evaporate THF before organism exposure. In their statistical analysis, there was no significant difference between toxicity of $\mathrm{TiO}_{2}$ solutions that had once contained THF and solutions that never had. However, sonicated $\mathrm{C}_{60}$, that was not treated with $\mathrm{THF}$, did not follow a trend of increasing

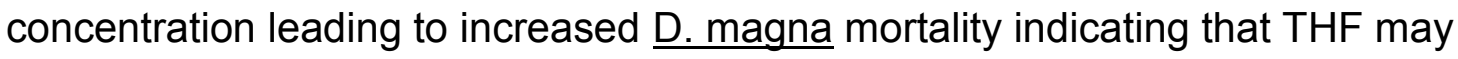
have been responsible for toxicity.

The properties of CNTs can vary greatly depending on the tube's diameter, and chirality, thus presenting problems when comparing toxicity data. For example, a toxicological assay may have been conducted using tubes of similar dimensions (e.g. single-walled carbon nanotubes) from different manufacturing sources can result in different outcomes. A change of one in the $(n, m)$ index of a tube's chirality, for example; comparing an $(8,6)$ tube to an $(8,7)$ (Figure 2), the absorption spectra is shifted into the near infrared by about 100 $\mathrm{nm}$ (Tu et al. 2009). By the same token, two tubes of the same chirality but 
differing length or diameter may also react differently to assay conditions. Very short tubes may be able to be phagocytosed, while longer tubes might not (Cheng 2009). This can further be complicated by surface functional groups.

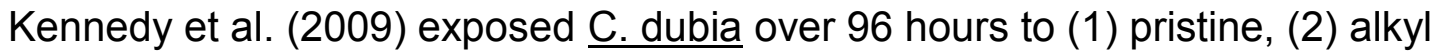
functionalized, (3) amine functionalized, and (4) hydroxylated MWNTs (Table 1). Surface functionalization greatly influenced toxicity.

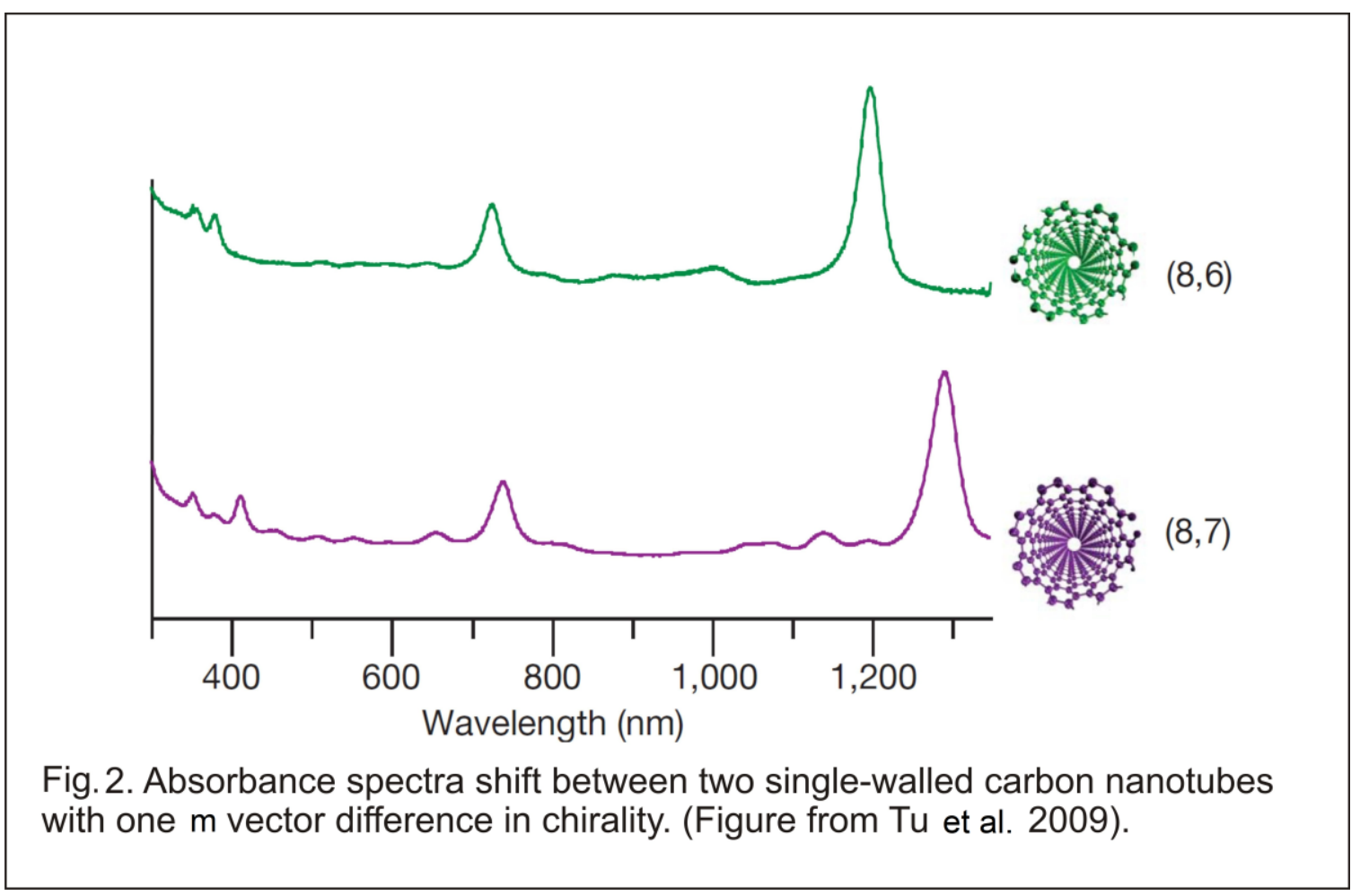


TABLE 1. Toxicity of multi-walled carbon nanotubes to Ceriodaphnia dubia influenced by surface functionalization (Table from Kennedy et al. 2009).

\begin{tabular}{|c|c|c|}
\hline & $\begin{array}{c}\text { Percent Survival with } \\
\text { Standard Deviaion }\end{array}$ & Exposure Concentration \\
\hline MWNT & $75 \pm 19$ & $16 \mathrm{ppm}$ \\
\hline MWNT & $25 \pm 19$ & $26 \mathrm{ppm}$ \\
\hline MWNT-NH 2 & $0 \pm 0$ & $2 \mathrm{ppm}$ \\
\hline MWNT-C8 & $0 \pm 0$ & $15 \mathrm{ppm}$ \\
\hline MWNT-OH & $93 \pm 12$ & $48 \mathrm{ppm}$ \\
\hline
\end{tabular}

\section{Carbon Nanotubes in Aquatic Ecosystems}

MWNTs can be suspended in the water column by means of natural organic matter (NOM), a ubiquitous constituent of natural aquatic systems (Hyung et al. 2008). Despite their natural hydrophobicity, interactions with NOM may stabilize MWNTs in aqueous suspension thus increasing the risk of exposure to pelagic organisms. NOM forms from the decomposition of plant and animal biomass. It consists of complex polyelectrolytes that can have a variety of molecular weights depending on their specific origin (Hyung et al. 2008). NOM typically has a negative charge due to carboxyl and phenol functional groups attached throughout the molecule (Hyung et al. 2008). Before publications demonstrating NOM adsorption behavior to CNTs, the only model known to suggest that NOM would readily adsorb to CNT surfaces was NOM behavior with activated carbon (Summers and Roberts 1988). NOM structure is affected by the ionic strength, and the $\mathrm{pH}$ of the water it is dissolved in (Hong and Elimelech 1997). Those parameters change the charge and molecular configuration of NOM by altering electrostatic repulsion within the molecule. In activated carbon it 
has been shown that NOM adsorption increases as ionic strength increases, but decreases as pH increases (Hong and Elimelech 1997).

In general, Hyung and Kim (2008) showed that with increasing hydrophobicity, adsorption capacity to CNT increases. This means that the more aromatic NOM varieties, such as humic acid, have greater intrinsic affinity for CNTs. Diameter may play a part in determining the degree to which NOM acids can stabilize tubes. Lin and Xing (2008) tested adsorption and stability of tannic acid to SWNTs and MWNTs of mean outer diameters from about $9 \mathrm{~nm}$ to $70 \mathrm{~nm}$ (Table 2). They found that the SWNTs -having a mean outer diameter mean of $0.4 \mathrm{~nm}$ - had very low stability with tannic acid, as well as the MWNTs with mean diameters under $40 \mathrm{~nm}$ (Figure 3).

TABLE 2. Table of the purity and measured diameters with standard deviation of the carbon nanotubes used in a tannic acid suspension study (table from Lin and Xing 2008).

\begin{tabular}{|c|c|c|c|}
\hline CNTs & purity $\%$ & \multicolumn{1}{c}{$\begin{array}{c}\text { length } \\
(\mu \mathrm{m})\end{array}$} & $\begin{array}{c}\text { outer diameter } \\
(\mathrm{nm})\end{array}$ \\
\hline SWCNT & $>90$ & $5-15$ & $1.4 \pm 0.4$ \\
\hline MWCNT10 & $>95$ & $1-2$ & $9.4 \pm 1.8$ \\
\hline MWCNT20 & $>95$ & $1-2$ & $20.9 \pm 3.0$ \\
\hline MWCNT40 & $>95$ & $1-2$ & $27.8 \pm 6.0$ \\
\hline MWCNT60 & $>95$ & $1-2$ & $42.7 \pm 6.4$ \\
\hline MWCNT100 & $>95$ & $1-2$ & $70.1 \pm 9.5$ \\
\hline
\end{tabular}




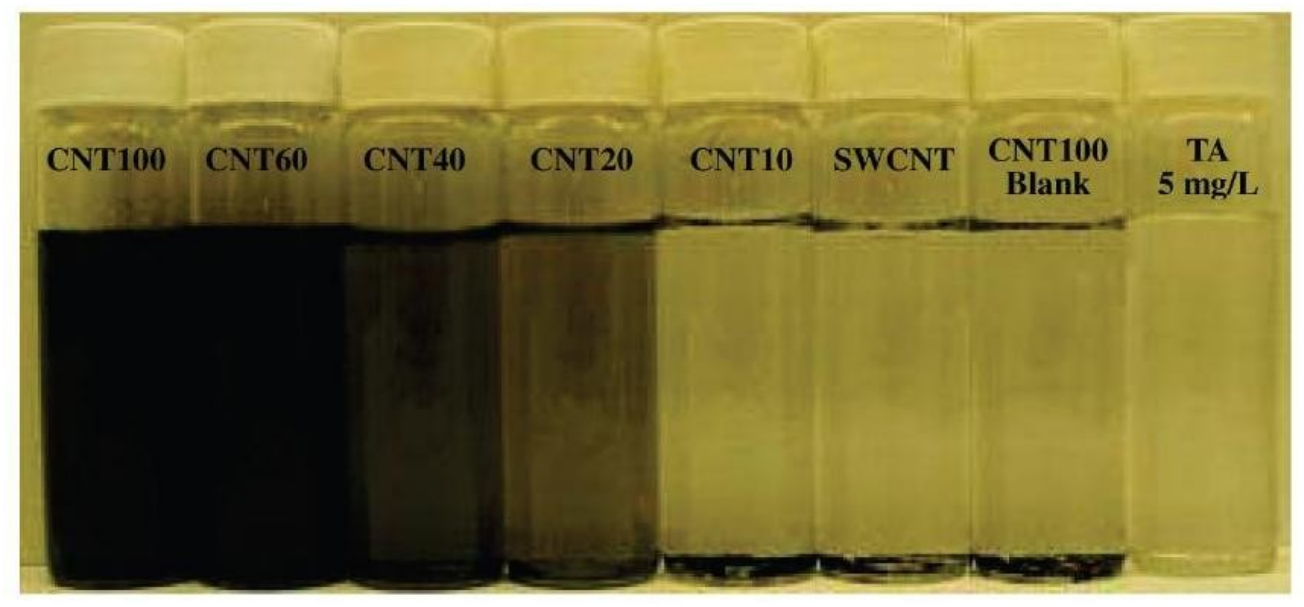

Fig. 3. Stability of single-walled carbon nanotubes and five diameter classes, 10 $\mathrm{nm}, 20 \mathrm{~nm}, 40 \mathrm{~nm}, 60 \mathrm{~nm}$, and $100 \mathrm{~nm}$ multi-walled carbon nanotubes in tannic acid. (Figure from Lin and Xing 2008).

Obligate fine mesh grazing zooplankton, such as in the case of two cladocerans, Ceriodaphnia dubia and Daphnia magna, have been shown to ingest suspended CNT aggregates (Roberts et al. 2007, Petersen et al. 2009, Kennedy et al. 2009). In the pelagic zone, grazing zooplankton are the main primary consumer. Trophic cascades, indirect effects at other trophic positions due to changes at lower levels, have been triggered in experimental lakes by manipulating the zooplankton population either by food source or predation pressure changes (Carpenter et al. 2001) The authors observed population trends in phytoplankton, zooplankton, planktivorous fish, and piscivorous fish, in lakes with nutrient additions. They reported that the presence or absence of predation manipulated the body size of dominant zooplankton populations, and that the primary production rate influenced the biomass production in all 
consumer levels. Thus, a food shortage or inhibition in feeding activities caused by a suspended material, would lower zooplankton populations, which in turn, would deprive the planktivorous species of food. Similar feeding inhibitions by suspended particles have already been described in the literature (Kirk 1990, 1992). Grazing limits the biomass of the zooplankton, which determines the possible biomass of the higher trophic positions. Carbon nanotubes, as a suspended material, may act in a similar manner as other suspended materials, by adversely affecting zooplankton growth and reproduction, and thus causing a cascade of energy deficiency up the food web. 


\section{GOALS AND HYPOTHESES}

The goal of this research is to investigate the effects of suspended multiwalled carbon nanotube (MVNT) aggregates on zooplankton growth and reproduction. Carbon nanotubes (CNTs) are hydrophobic nanomaterials that are largely insoluble in water. However, interactions with surfacewater constituents such as natural organic matter (NOM) can result in relatively stable suspensions of CNTs. Previous research examining the toxicity of CNTs to zooplankton, observed toxicity (mortality) only at the highest test concentrations (Roberts et al. 2007). Other studies (Kirk 1990, 1992) have shown effects of suspended clays on daphnid growth. These findings lead to the following hypotheses:

Hypothesis 1: Suspended CNTs result in decreased growth and reproduction in grazing zooplankton.

Ingested CNTs inhibit normal grazing and assimilation of food in the digestive tract. The resulting energetic cost affects growth of the organism. Decrease in body size ultimately reduces the fitness of the organism by reducing reproductive potential. My first hypothesis was tested using a series of chronic and acute toxicity tests in which Daphnia magna and Ceriodaphnia dubia were exposed to varying concentrations of MWNTs suspended in NOM.

Hypothesis 2: Variation in $\mathrm{pH}$ has a significant effect on MWNT toxicity.

NOM changes structure with strong variation in $\mathrm{pH}$ (Hong and Elimelech 1997). This, in turn, could change adsorption of NOM to MWNTs. A change in 
NOM adsorption might change the behavior of MWNT aggregates in freshwater, which might alter toxicity to grazing zooplankton. My second hypothesis was tested using a series of chronic and acute toxicity tests in which $\underline{\mathrm{D}}$. magna and $\underline{\mathrm{C}}$. dubia were exposed to varying concentrations of MWNTs suspended in NOM in freshwater of different pHs. 


\section{METHODS}

\section{Material Preparation}

Water preparation reagents were obtained from Fisher Scientific (Pittsburg, Pennsylvania, USA). Multi-walled carbon nanotubes (MWNTs) were obtained from NanoAmor (Houston, Texas, USA). Because natural organic matter (NOM) in natural surface waters varies widely in composition, for this study Suwannee River natural organic matter, a natural mix uncontrolled for NOM species composition, was used (International Humic Substances Society, St. Paul, Minnesota, USA).

Reconstituted moderately hard water (RHW) was prepared to the Environmental Protection Agency (EPA) standards (Table 3) (US EPA 2002). Pure water was obtained by recirculation of reverse osmosis deionized water through a system consisting of approximately four liters of granulated activated carbon, and a MilliQ purifier with another carbon column and two ion exchange columns. Water was allowed to recirculate through the system for at least 24 hours before being pumped into a $50 \mathrm{~L}$ carboy with the appropriate amounts of dissolved salts.

NOM was mixed into the RHW to a concentration of $15 \mathrm{mg} \mathrm{NOM} / \mathrm{L}$. This was the concentration used as water for all MWNT suspensions referred to hereafter. 
TABLE 3. Moderately hard water preparation and quality parameters.

\begin{tabular}{|c|c|c|c|c|c|c|}
\hline \multicolumn{3}{|c|}{ Reagent added in mg per $\mathrm{L}$} & \multicolumn{5}{c|}{ Expressed as mg $\mathrm{CaCO}$ per $\mathrm{L}$} \\
\hline $\mathrm{NaHCO}_{3}$ & $\mathrm{CaSO}_{4} \cdot \mathrm{H}_{2} \mathrm{O}$ & $\mathrm{MgSO}_{4}$ & $\mathrm{KCl}$ & $\mathrm{pH}$ & Hardness & Alkalinity \\
\hline 96 & 60 & 60 & 4 & $7.4-7.8$ & $80-100$ & $57-64$ \\
\hline
\end{tabular}

To make MWNT test suspensions, the desired amount of MWNTs was weighed using a Cahn C-31 microbalance to one tenth of a microgram. The weighed amount of MWNTs was placed into a 100mL borosilicate glass centrifuge tube with $100 \mathrm{~mL}$ of NOM solution. The MWNTs were sonicated with a Fisher model 500 sonic dismemberator for thirty minutes at an average of 100 watts of power. This prepared a stock suspension used to make exposure suspensions by dilution using NOM solution adjusted to the desired $\mathrm{pH}$.

All test chambers, pipettes, flasks, and volumetric glassware used were borosilicate glass to avoid possible hydrophobic reactions with plastics. Aluminum foil was used for weighing boats in the preparation of NOM solutions and CNT stock suspensions. 


\section{Material Characterization}

\section{$\underline{\text { Stock Characteristics }}$}

NanoAmor reported the purity of MWNTs purchased to be greater than $95 \%$, the outer diameter to be within the range of $20 \mathrm{~nm}$ to $30 \mathrm{~nm}$, and the length to be between $0.5 \mu \mathrm{m}$ to $2 \mu \mathrm{m}$.

\section{S.E.M. Characterization}

MWNTs were dispersed by the methods described above, except MilliQ water was used instead of RHW to reduce the number and size of salt crystals in a dry sample. Samples were prepared at 5ppm MWNTs in suspensions adjusted to $\mathrm{pH} 6,7$, and 8 to image aggregate formation at those $\mathrm{pHs}$. Drop-wise aliquots were placed on cleaned glass cover slips and allowed to dry in a low humidity environment with Petri dish covers to minimize contamination of the samples by dust. All samples were sputter coated with a gold-palladium alloy and imaged (Nova Field Emission Gun Scanning Electron Microscope, FEI North America, Hillsboro, Oregon USA). Aggregate diameter means was determined by measuring each aggregate along four angles and calculating the mean as the aggregate diameter.

\section{Dynamic Light Scattering}

Mean aggregate size in aqueous phase suspension was measured using dynamic light scattering on a Malvern instruments Zeta Sizer (Worcestershire, U.K.) Nano Series model ZS with a DTS1060C clear disposable zeta cell. Each 
sample was prepared with RHW and NOM concentrations as described earlier. All three $\mathrm{pH}$ adjustments $(6,7$, and 8$)$ were analyzed at 5ppm MWNT.

\section{$\underline{\text { Zeta Potentials }}$}

Zeta potential was measured using a Malvern instruments Zeta Sizer (Worcestershire, U.K.) Nano Series model ZS with a DTS1060C clear disposable zeta cell. A refractive index of 1.12 and absorbtion coefficient of 39.92 was used to calculate surface charge. Each sample was prepared with RHW and NOM concentrations as described earlier. All three $\mathrm{pH}$ adjustments $(6,7$, and 8$)$ were analyzed at 5ppm MWNT.

\section{Test Organisms}

\section{Ceriodaphnia dubia}

C. dubia is a model organism firmly established in aquatic toxicity testing literature. It has been used in US EPA protocols for at least 24 years, having been described in US EPA publications in 1986, but in the literature for about 116 years (Richard 1894). It has a recognized distribution across most surface waters.

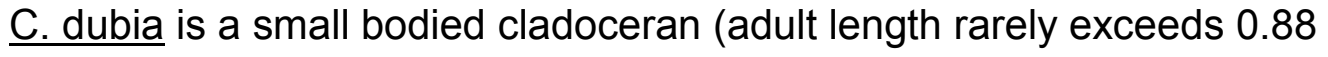
$\mathrm{mm}$ ) and has a short generation time. It is a parthenogenetic species and does not produce males under normal circumstances. A variety of predators prey upon C. dubia, including the mysids, Chaoborus larvae, and copepods. In the wild, an individual organism rarely survives beyond its third brood, thus making its total 
reproduction of those three broods the most ecologically important (USEPA 1986).

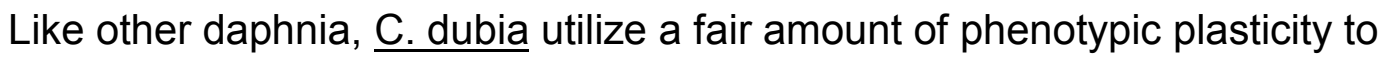
react to predation and other stressors. They have been observed to alter the mean time to first brood, brood sizes, and even offspring size in reaction to various pressures (Lynch 1979). Under standard testing conditions of a 16:8 photoperiod, $24^{\circ} \mathrm{C}$, and ad libitum feeding, numbers of neonates per brood ranges from 6 to 10, but individual broods greater than twenty are not unheard of (USEPA 1986). Standard EPA test protocol requires a 3-brood mean of at least 15.

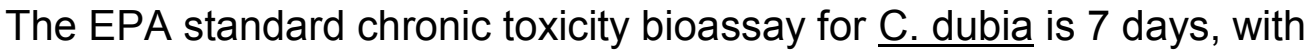
three broods expected from controls in that time. USEPA testing protocol calls for a control survival of $80 \%$ or greater and a mean brood size of 15 or more to have valid tests.

\section{Daphnia magna}

D. magna is another model organism extensively utilized in aquatic toxicity work. It is much larger than $\underline{\mathrm{C} \text {. dubia, }}$ growing as large as $6.0 \mathrm{~mm}$ as an adult instar. Like $\underline{\text { C. dubia, }}$ D. magna has been known to the literature for more than one hundred years (Straus 1820). Its distribution is also multi-continental (USEPA 1986).

D. magna parthenogenetic reproduction is quite similar to $\underline{\text { C. dubia, but on }}$ a longer time scale. In 21 days an individual can be expected to be born, grow, 
and produce 3 broods totaling more than 40 neonates. Average brood sizes vary from 10 to 15, but large individuals producing as many as 57 neonates in a single, huge, brood has been documented (US EPA 1986).

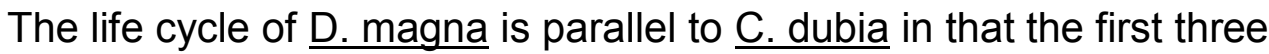
broods are the most ecologically important even though the organism can live in a controlled environment long enough to produce as many as 22 broods.

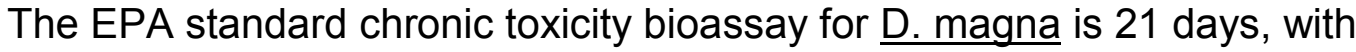
three broods expected from controls in that time. EPA testing protocol calls for a control survival of $80 \%$ or greater and a mean brood size of 40 or more to have valid tests.

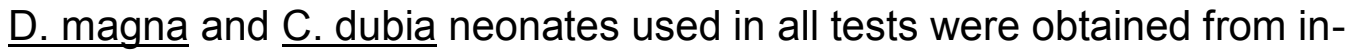
house cultures maintained in RHW, prepared as described by the EPA. Stock cultures were fed a diet of Selenastrum capricornutum and Cerophyll.

S. capricornutum was cultured in RHW under constant light with algal growth nutrients added. Nutrients were separated from algae by centrifugation, supernatant extraction, and resuspension in RHW without nutrients added. The Cerophyll was prepared by homogenizing 2 grams standardized alfalfa with $250 \mathrm{~mL} R H W$, settling overnight, and then extracting the supernatant.

Bioassays

$\underline{\text { Acute Tests }}$

Three acute tests were run for each test organism. A test at pH $7.0 \pm 0.2$ for all exposure and control waters, and two similar tests with $\mathrm{pH}$ varied to $6.0 \pm$ 
0.2 and to $8.0 \pm 0.2$ by means of additions of hydrochloric acid, and sodium hydroxide respectively. All tests used EPA standard RHW, and all exposure waters had an addition of NOM to $15 \mathrm{mg} / \mathrm{L}$.

All tests were performed in a climate controlled environmental chamber with a photoperiod of $16 \mathrm{hr}$ light, $8 \mathrm{hr}$ dark, with a constant temperature of $22.5^{\circ} \mathrm{C}$. Solutions were renewed daily, and food $(100 \mu \mathrm{L}$ Cerophyll, $200 \mu \mathrm{L} \underline{\mathrm{S}}$.

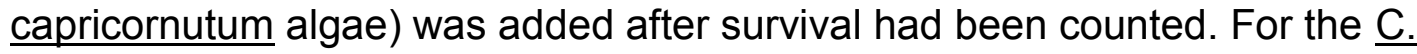
dubia tests, three hundred neonates per test were used. Treatments and controls consisted of five replicates of ten individual neonates per replicate (Figure 4).There were two controls: a RHW without NOM control and a NOM solution control. There were four exposure treatments with concentrations of $0.5,1.0$, 2.0, and $4.0 \mathrm{ppm}$ MWNT for $\mathrm{pH}$ 7, and 1, 2, 4 and 10ppm for $\mathrm{pH} 6$ and $8 \underline{\mathrm{C} \text {. dubia }}$ tests.

For $\underline{D}$. magna acute tests, controls and treatments consisted of five replicates of ten neonates each (Figure 5). Exposure concentrations for $\underline{D}$. magna were 1 and 10ppm MWNT. Additionally, the D. magna $\mathrm{pH} 7$ test was limited to only 5 individual organisms per replicate instead of the 10 per replicate used in all of the other tests.

The logistical challenges in both sample handling, and measurements of

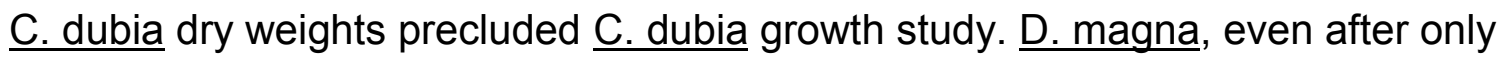
96 hrs, typically grows far larger than any adult $\underline{\text { C. dubia and handling of freeze- }}$ 
dried organisms for mass analysis can be performed without unacceptable damage to samples during handling.

An acute survival test was conducted on D. magna using the same methods as described above, but at the termination of the test the organisms were depurated in clean RHW for $4 \mathrm{hrs}$ before freezing at $-80^{\circ} \mathrm{C}$. Frozen organisms were lyophilized (Freezone 6, Labconco, Kansas City, Missouri, USA) before measuring dry weights using a Cahn C-31 microbalance.

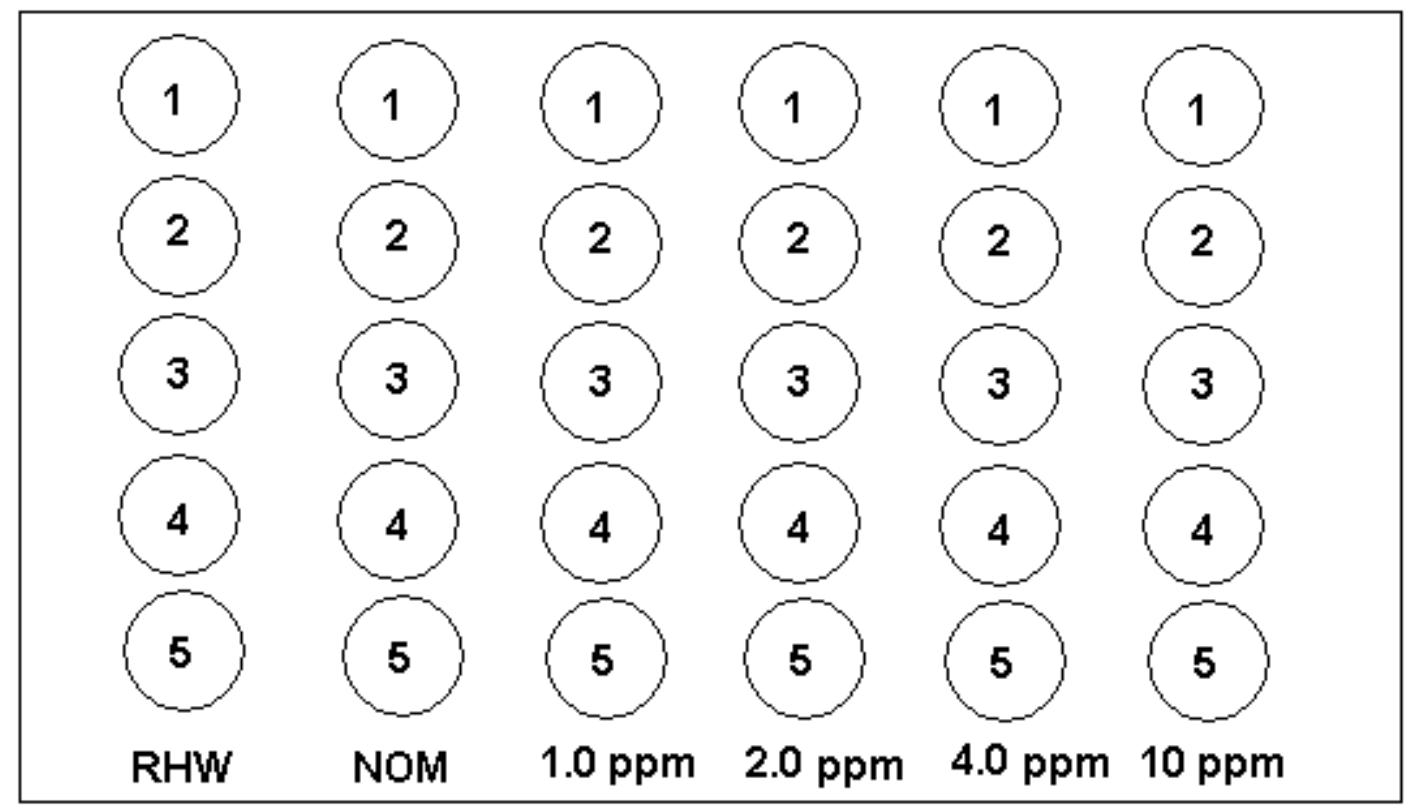

Fig. 4. Ceriodaphnia dubia test board arrangement for $96 \mathrm{hr}$ acute exposure survival tests. 


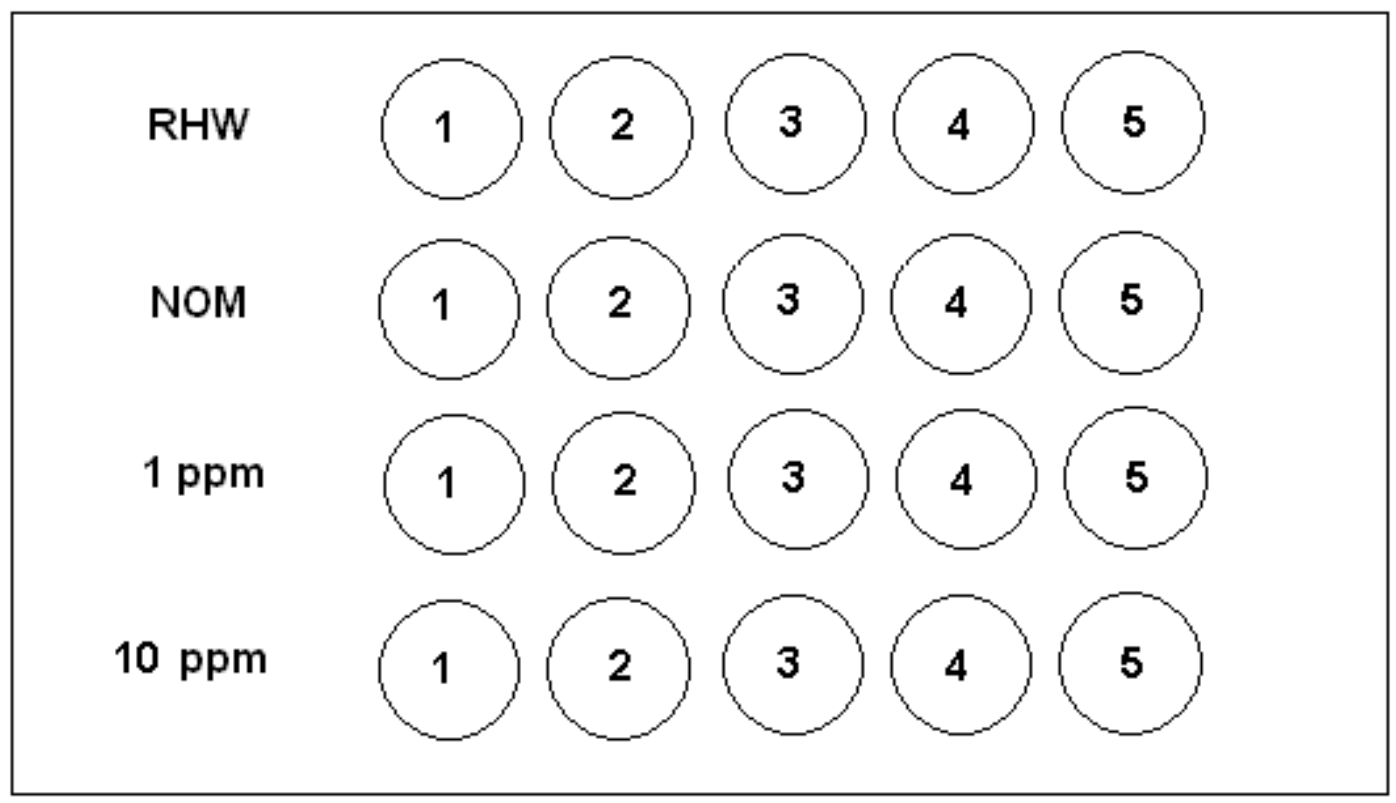

Fig. 5. Daphnia magna test board arrangement for $96 \mathrm{hr}$ acute exposure survival tests and $96 \mathrm{hr}$ growth tests.

\section{$\underline{\text { Chronic Tests }}$}

Neonates were divided up into a moderately hard water control group of 10 replicates, and a NOM control group of 10 replicates with 4 different exposure groups of 10 replicates (Figure 6). Each individual test organism was held in 15 $\mathrm{mL}$ of exposure media in $30 \mathrm{~mL}$ glass beaker. 


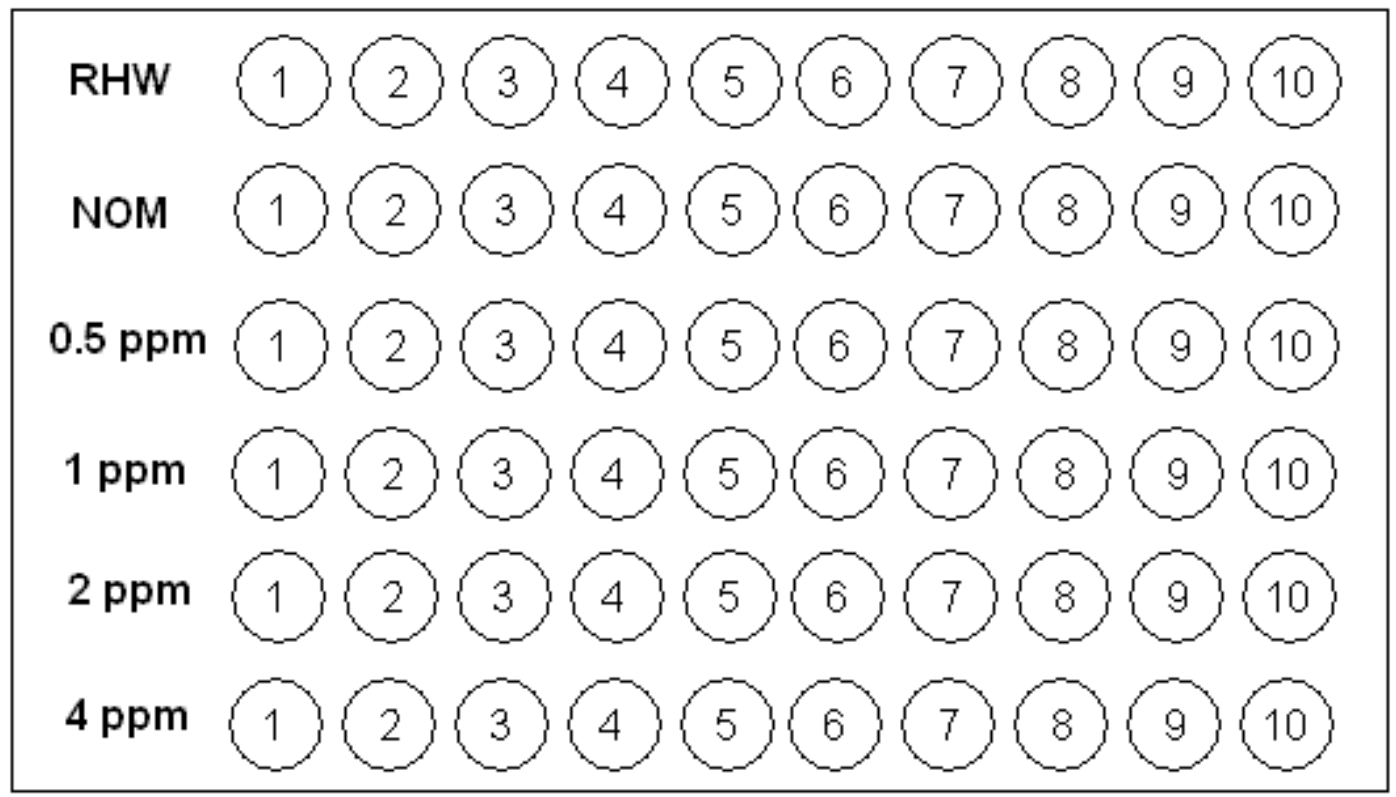

Fig. 6. Chronic test board arrangement for both Daphnia magna (21 day chronic) and Ceriodaphnia dubia (7 day chronic).

Test suspensions were renewed daily along with counts of mortality, and reproduction. After renewal and counts, the organisms were fed $200 \mu \mathrm{L} 2.0 \times 10^{5}$ cells $/ \mathrm{ml}$ of $\underline{\mathrm{S}}$. capricornutum and $100 \mu \mathrm{L}$ Cerophyll. Daily renewal continued until

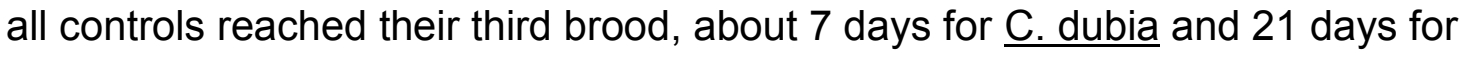
D. magna.

\section{Data Analysis}

All data analyses were run on SAS Version 9.2 (SAS Institute Inc., Cary, NC, USA) and all tests for significance used an alpha value of 0.05 . Before any multisample test was run, Grubb's test was used to check for outliers. 
Acute survival was analyzed as percent of control survival with arcsine transformation used to meet analysis of variance (ANOVA) assumption of homogeneity of variances. A one factor, exposure concentration, ANOVA using survival expressed as a percentage of control survival with arcsine transformation, followed by a Tukey's post-hoc test was used to group any differences in survival. A two-factor, $\mathrm{pH}$ and exposure concentration, ANOVA using survival as percentage of control with arcsine transformation, followed by a Tukey's post-hoc test was used when comparing acute tests across pHs.

Chronic reproduction was analyzed as percent of control mean reproduction. The percentage data was arcsine transformed to meet ANOVA assumptions of homogeneity of variances. A one-factor, exposure concentration, ANOVA using percentage of control reproduction with arcsine transformation, followed by a Tukey's post-hoc test was used to group differences in reproduction. Two-factor, $\mathrm{pH}$ and exposure concentration, ANOVA followed by Tukey's post-hoc test was used when comparing chronic tests across pHs. In all tests, an alpha value of 0.05 was used in determining significance. 


\section{RESULTS \\ Material Characterization \\ Scanning Electron Microscope}

The mean aggregate diameter for multi-walled carbon nanotubes (MWNTs) at pH 7 was $6.5263 \mu \mathrm{m}$ with a standard deviation of $2.3741 \mu \mathrm{m}$. The mean for $\mathrm{pH} 6$ was $9.1725 \mu \mathrm{m} \pm 6.7533 \mu \mathrm{m}$, and $\mathrm{pH} 8$ was $2.2557 \mu \mathrm{m} \pm 0.9635$ $\mu \mathrm{m}$ (Table 4, Figure 7).

\section{Dynamic Light Scattering}

The mean aggregate diameter for MWNTs in $\mathrm{pH} 7$ NOM solution was $149.2 \mathrm{~nm}$. The mean aggregate diameters in $\mathrm{pH} 6$ and $\mathrm{pH} 8$ were $129.1 \mathrm{~nm}$ and $142.4 \mathrm{~nm}$, respectively (Table 4).

\section{Zeta Potential}

The zeta potential of MWNTs in $\mathrm{pH} 7 \mathrm{NOM}$ solution was measured to be 23.3 $\mathrm{mV}$. The zeta potentials of $\mathrm{pH} 6$ and $\mathrm{pH} 8$ were $-21.7 \mathrm{mV}$ and $-25.8 \mathrm{mV}$, respectively (Table 4 ). 
TABLE 4. Variation of mean multi-walled nanotube aggregate size as measured by

Scanning Electron Microscope, and Dynamic Light Scattering. Change in Zeta

Potential among three $\mathrm{pH}$ adjustments.

\begin{tabular}{|c|c|c|c|c|}
\hline & \multicolumn{2}{|c|}{ Mean diameter measured by SEM } & DLS & Zeta Potential \\
\hline $\mathrm{pH} 6$ & $9.17245 \pm 6.7533 \mu \mathrm{m}$ * & $n=32$ & $129.1 \mathrm{~nm}$ & $-21.7 \mathrm{mV}$ \\
\hline $\mathrm{pH} 7$ & $6.52635 \pm 2.3741 \mu m^{*}$ & $n=40$ & $149.2 \mathrm{~nm}$ & $-23.3 \mathrm{mV}$ \\
\hline $\mathrm{pH} 8$ & $2.25577 \pm 0.9634 \mu m^{*}$ & $n=24$ & $142.2 \mathrm{~nm}$ & $-25.8 \mathrm{mV}$ \\
\hline
\end{tabular}

${ }^{*}$ Significant at an alpha $=0.05$

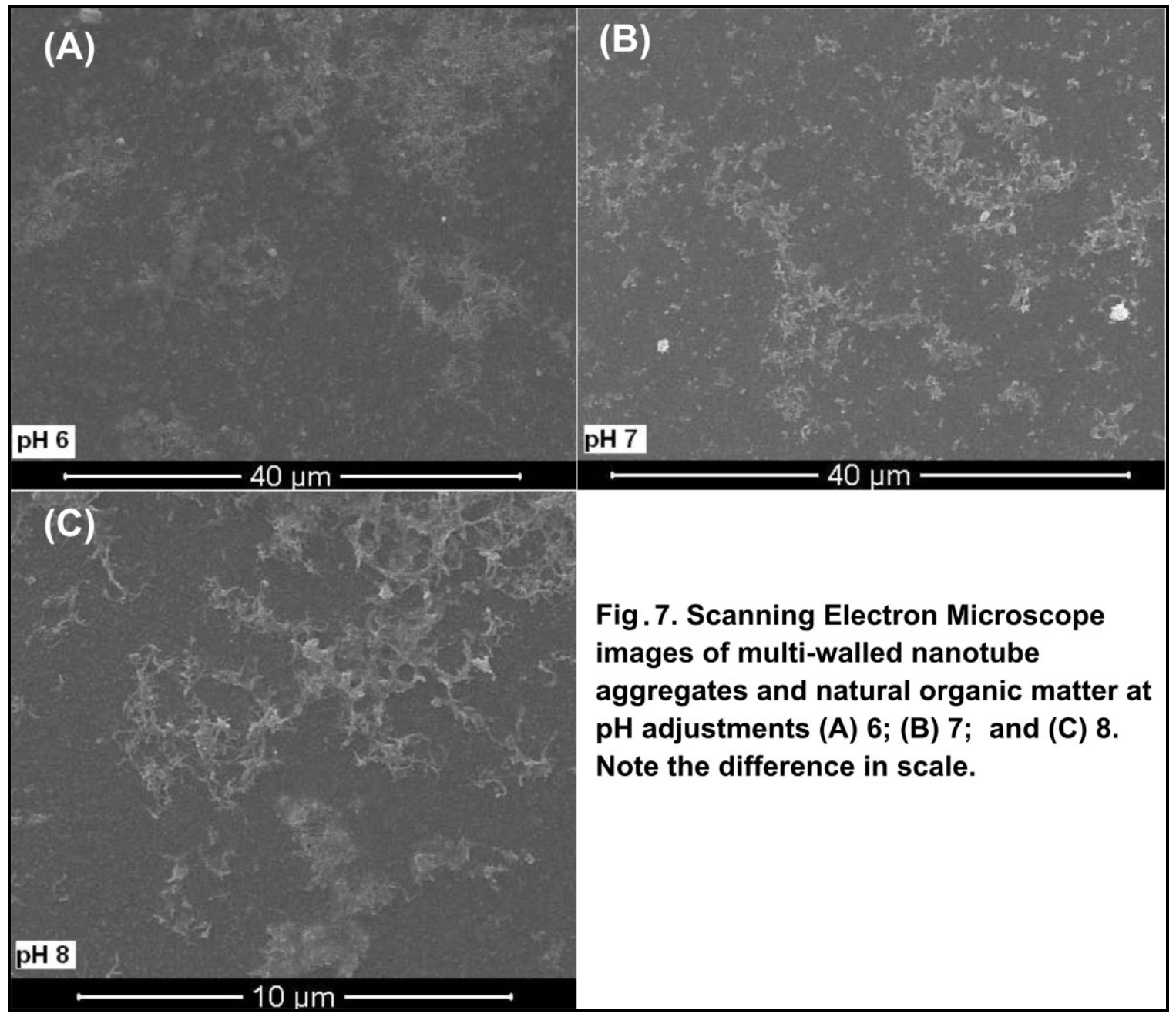




\section{Survival}

There was no significant difference in survival over the observed 96hrs in the Ceriodaphnia dubia acute test at $\mathrm{pH} 7$ (ANOVA $\mathrm{F}=1.49 \mathrm{p}=0.231$ )(Figure 8 , Table 5). Mean transformed percent survival across the test was $84.65 \pm 9.97$. $\underline{\text {. }}$ dubia survival was not different with $\mathrm{pH}$ adjustments (ANOVA $\mathrm{F}_{\mathrm{pH} 6}=1.47 \mathrm{p}_{\mathrm{pH} 6}$ $\left.=0.235 ; \mathrm{F}_{\mathrm{pH} 8}=1.45 \mathrm{p}_{\mathrm{pH} 8}=0.243\right)$. When run as a two-factor ANOVA using $\mathrm{pH}$ and exposure as factors the overall model is not significant (ANOVA $F=1.70$ $p=0.1008)$ (Figure 9, Table 4), indicating that there was no significant interactive effect between $\mathrm{pH}$ and exposure concentration on survival. The mean transformed percent survival across the test was $82.03 \pm 11.79$. Among the three C. dubia tests, $\mathrm{pH}$, as a factor by itself, did significantly influence survival in the observed time period (ANOVA $p=0.0430)$.

There was complete survival in the Daphnia magna $\mathrm{pH} \mathrm{7,96} \mathrm{hr} \mathrm{acute} \mathrm{test,}$ no statistics were used since there was no variance in that test. In the other $\underline{D}$. magna tests there was also a lack of significant difference between survival over 96 hrs from exposure groups and control groups, though not as dramatic, $\left(\right.$ ANOVA $\left.F_{p H 6}=1.0 p_{p H 6}=0.3466 ; F_{p H 8}=2.67 p_{p H 8}=0.1411\right)($ Figure 10, Table 5). When run as a two-factor ANOVA using $\mathrm{pH}$ and exposure as factors the overall model is not significant (ANOVA $F=1.88 p=0.1346$ ). The mean transformed percent survival across the test was $88.29 \pm 4.89$. Among the three D. magna tests, $\mathrm{pH}$ did not significantly influence survival in the observed time period (ANOVA $p=0.2568)$. 


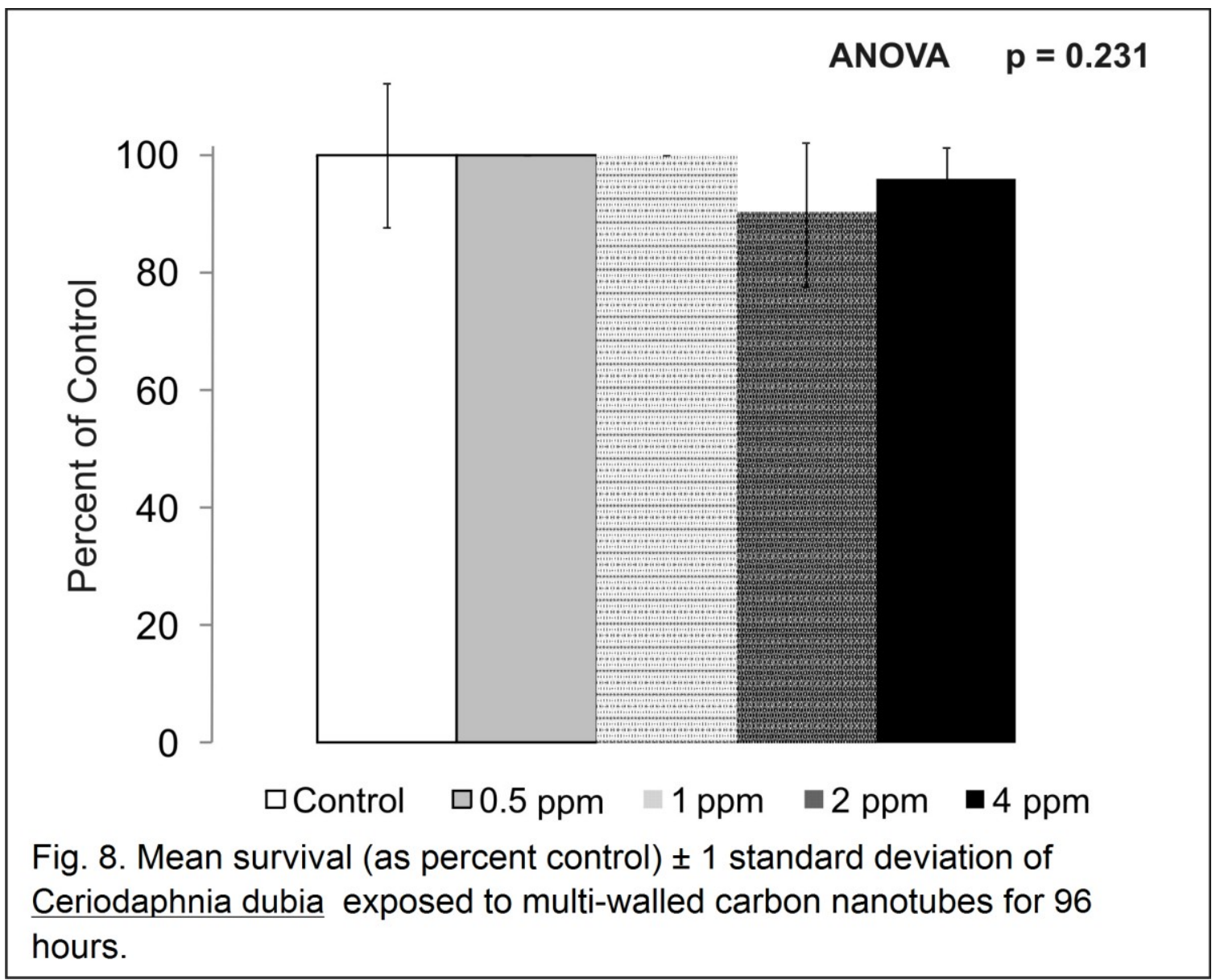




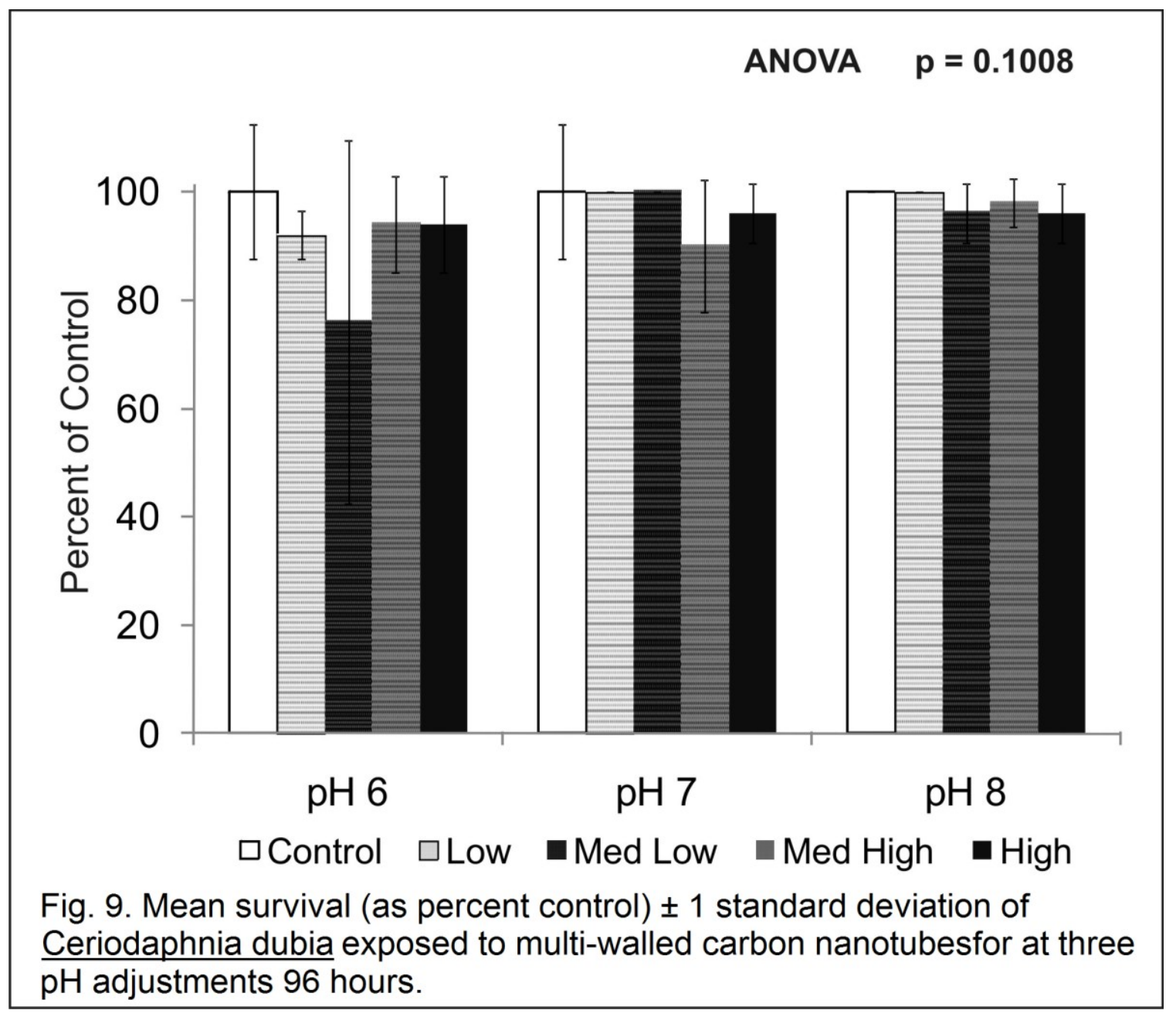




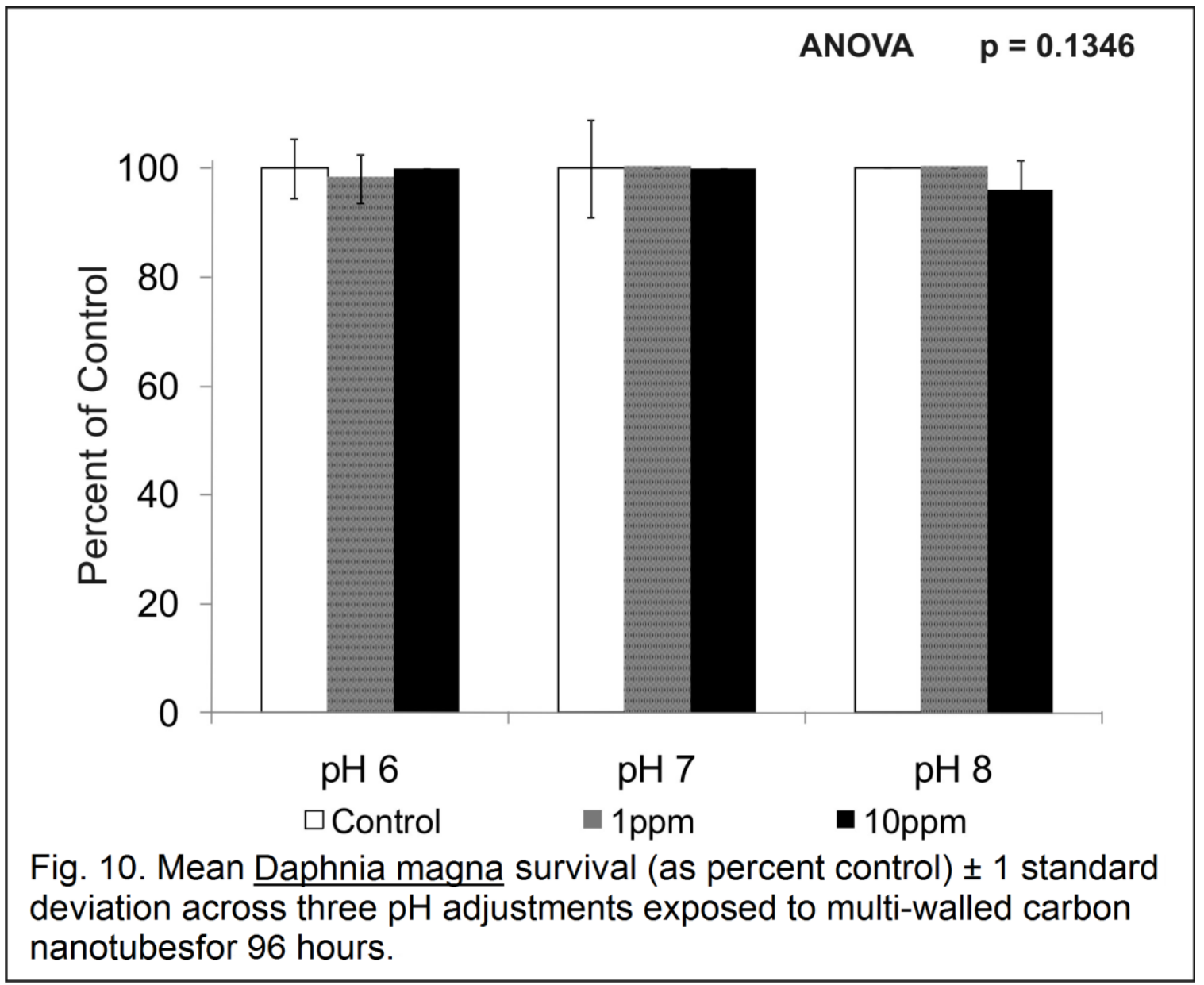


TABLE 5. $96 \mathrm{hr}$ Acute survival test means (as percent control) \pm 1 standard deviation.

\begin{tabular}{|c|c|c|c|c|}
\hline \multicolumn{5}{|c|}{ Mean Percent of Control with Standard Devation } \\
\hline \multirow{3}{*}{$\mathrm{pH} 7$} & $0.5 \mathrm{ppm}$ & $1 \mathrm{ppm}$ & 2ppm & 4ppm \\
\hline & $100 \pm 0$ & $100 \pm 0$ & $90 \pm 12.24$ & $96 \pm 5.48$ \\
\hline & \multicolumn{2}{|l|}{ 1ppm } & 4ppm & 10ppm \\
\hline $\mathrm{pH} 6$ & $92 \pm 4.47$ & $76 \pm 33.61$ & $94 \pm 8.94$ & $94 \pm 8.94$ \\
\hline ph 8 & $100 \pm 0$ & $96 \pm 5.48$ & $98 \pm 4.47$ & $96 \pm 5.48$ \\
\hline \multicolumn{5}{|c|}{ Daphnia maqna } \\
\hline & \multicolumn{2}{|r|}{ 10ppm } & & \\
\hline $\mathrm{pH} 6$ & $98 \pm 4.47$ & $100 \pm 0$ & & \\
\hline $\mathrm{pH} 7$ & $100 \pm 0$ & $100 \pm 0$ & & \\
\hline $\mathrm{pH} 8$ & $100 \pm 0$ & $96 \pm 5.47$ & & \\
\hline
\end{tabular}

\section{Growth}

There was a significant difference between mean dry body masses of exposed D. magna relative to controls (ANOVA $F=12.71 p=0.0014$ ). The mean dry weight was $36.04 \pm 3.48 \mu \mathrm{g}$. Relative to control the $5 \mathrm{ppm}$ MWNT exposure showed a $21.55 \%$ reduction in dry mass, and the $10 \mathrm{ppm}$ MWNT exposure showed a $23.06 \%$ reduction in dry mass. Tukey's post-hoc grouping placed both MWNT exposures together (Figure 11, Table 6).

Across three $\mathrm{pH}$ adjustments, there was a significant difference between the dry weights of $\underline{D}$. magna (ANOVA F $=7.5 p=0.0003$ ). Individually, both $p H$ $(p=0.0004)$ and exposure concentration $(p=0.0033)$ proved significant in the ANOVA, but there was no significant observed interactive effect between $\mathrm{pH}$ and exposure concentration ( $p=0.1659)$. Tukey's post-hoc test grouped $\mathrm{pH} 6$ and $\mathrm{pH}$ 8 together, but placed pH 7 into its own group (Figure12, Table 6). 


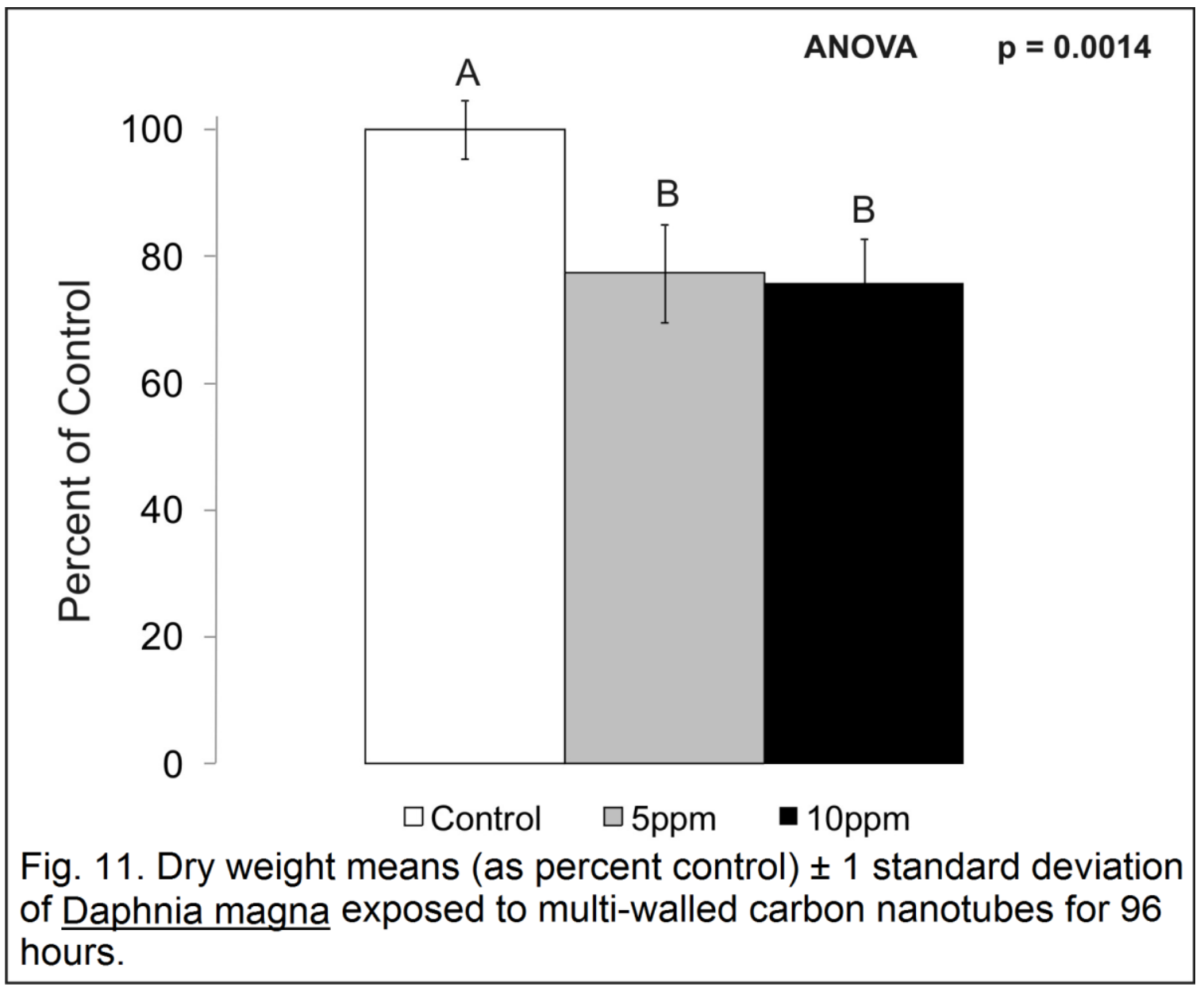




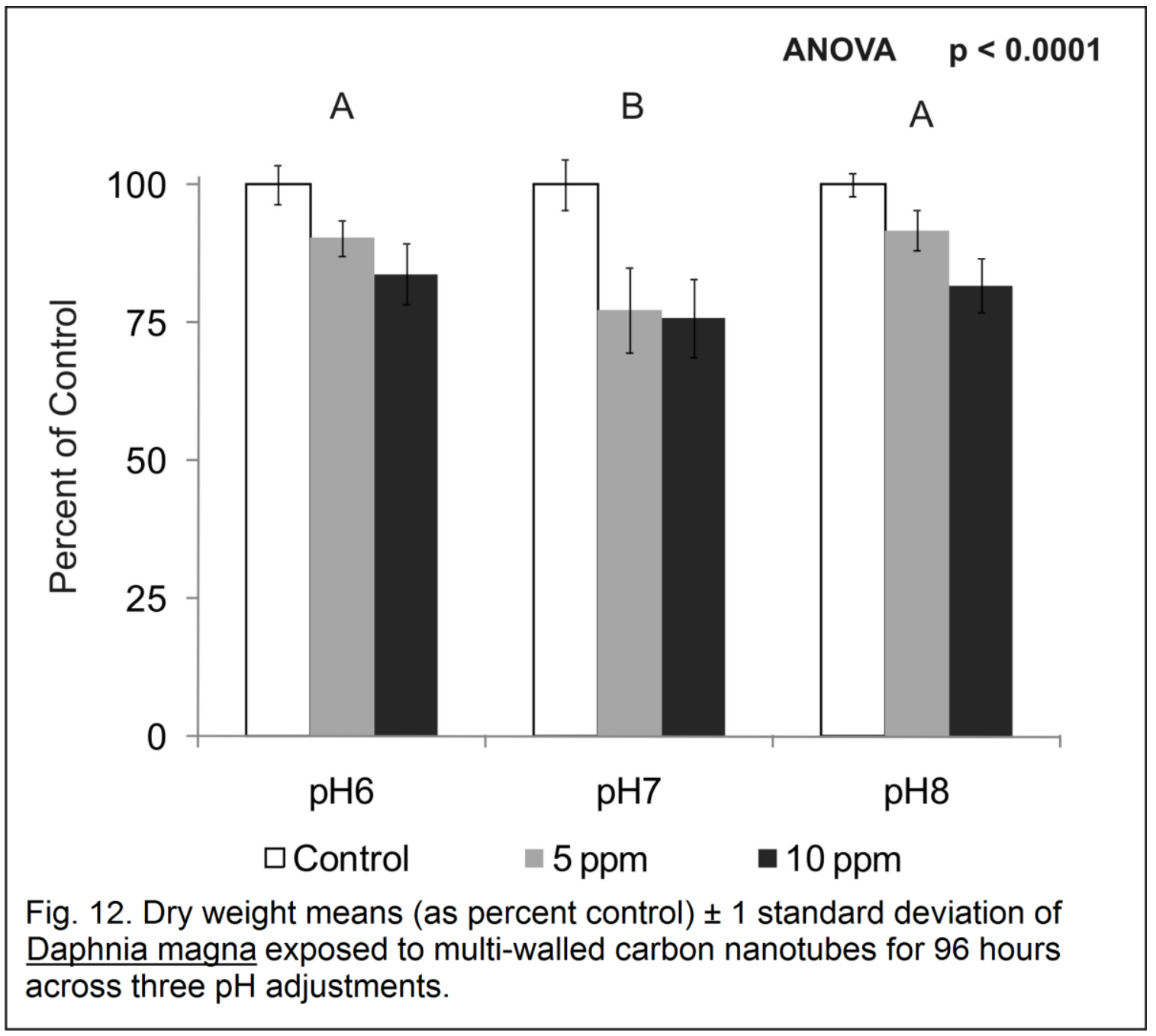

TABLE 6. Dry weigth means (as percent control with arcsine transformation) \pm 1 standard deviation of Daphnia magna exposed to MWNTs for 96 hrs with three $\mathrm{pH}$ adjustments.

\begin{tabular}{|c|c|c|}
\hline \multicolumn{3}{|c|}{ Mean dryweight with SD } \\
& Low Exposure & High Exposure \\
\hline $\mathrm{pH} \mathrm{6}$ & $72.07 \pm 3.01$ & $66.51 \pm 4.29$ \\
\hline $\mathrm{pH} \mathrm{7}$ & $61.81 \pm 5.18$ & $60.70 \pm 4.89$ \\
\hline $\mathrm{pH} 8$ & $73.60 \pm 3.93$ & $64.86 \pm 3.71$ \\
\hline
\end{tabular}


Reproduction

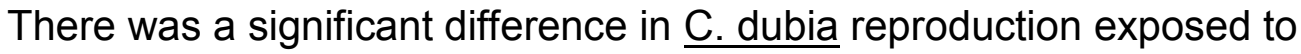
three concentrations of MWNTs (ANOVA F=9.21 $p=0.0002$ ). The exposure concentrations were $0.5 \mathrm{ppm}, 2.5 \mathrm{ppm}, 5 \mathrm{ppm}$ MWNT. Only the highest exposure was significantly different from the control (Figure 13, Table 7).

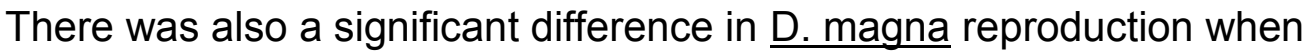
exposed to varying concentrations of MWNTs for three broods (ANOVA F=6.61 $\mathrm{p}=0.0005)$. Exposure concentrations were: $0.125 \mathrm{ppm}, 0.25 \mathrm{ppm}, 0.5 \mathrm{ppm}$, and 1.0ppm MWNTs. The lowest exposure's mean reproduction was not significantly different from the control (Figure 14, Table 7). The control was significantly different from the three highest exposures, however, none of the exposures were significantly different from each other.

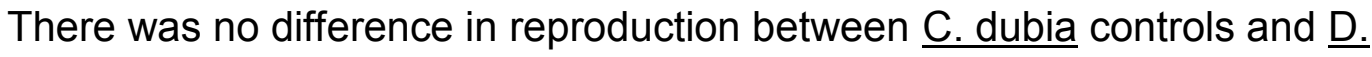
magna controls (Welch's Approximate t test $p=0.2014$ ). There was, however, a significant difference between the reproduction of $\underline{\mathrm{C} \text {. dubia exposed to } 0.5 \mathrm{ppm}}$ MWNTs and D. magna exposed to $0.5 p p m$ MWNTs (Student's $t$ test $p=0.002$ ).

\section{Reproduction with Variation in $\mathrm{pH}$}

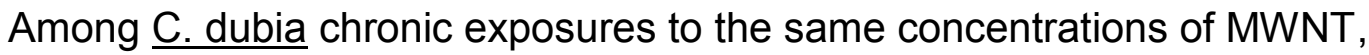
but among $\mathrm{pH}$ adjustments to $\mathrm{pH} 6, \mathrm{pH} 7$, and $\mathrm{pH} 8$, there was a significant difference among treatments (ANOVA $F=10.81 p<0.0001$ ). There was a significant difference among $\mathrm{pHs}(\mathrm{p}=0.0018)$ and among exposures $(\mathrm{p}=0.0001)$, 
but no observed significant interaction between MWNTs and $\mathrm{pH}$ variation $(p=0.1791)($ Figure 15, Table 7). 


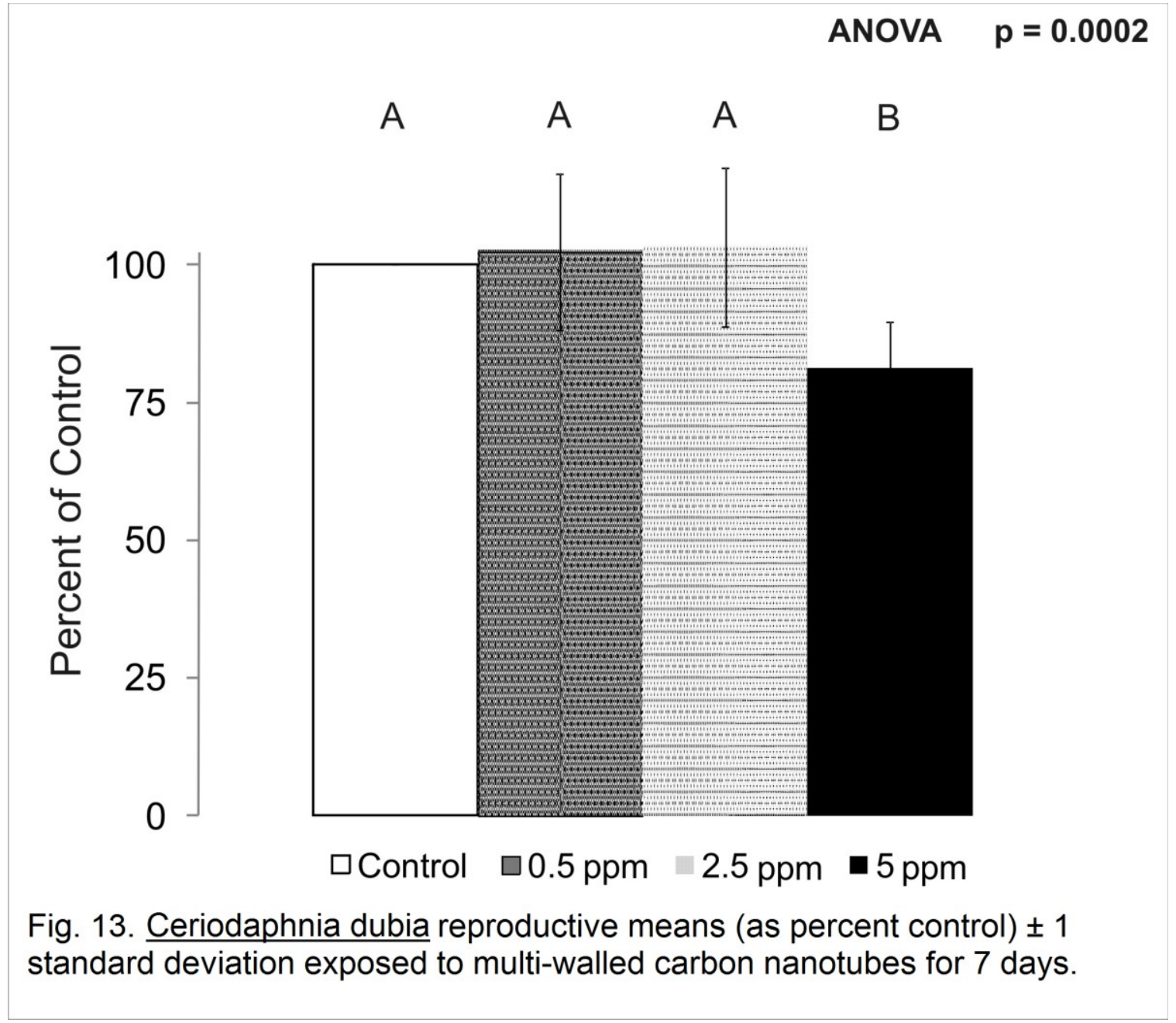




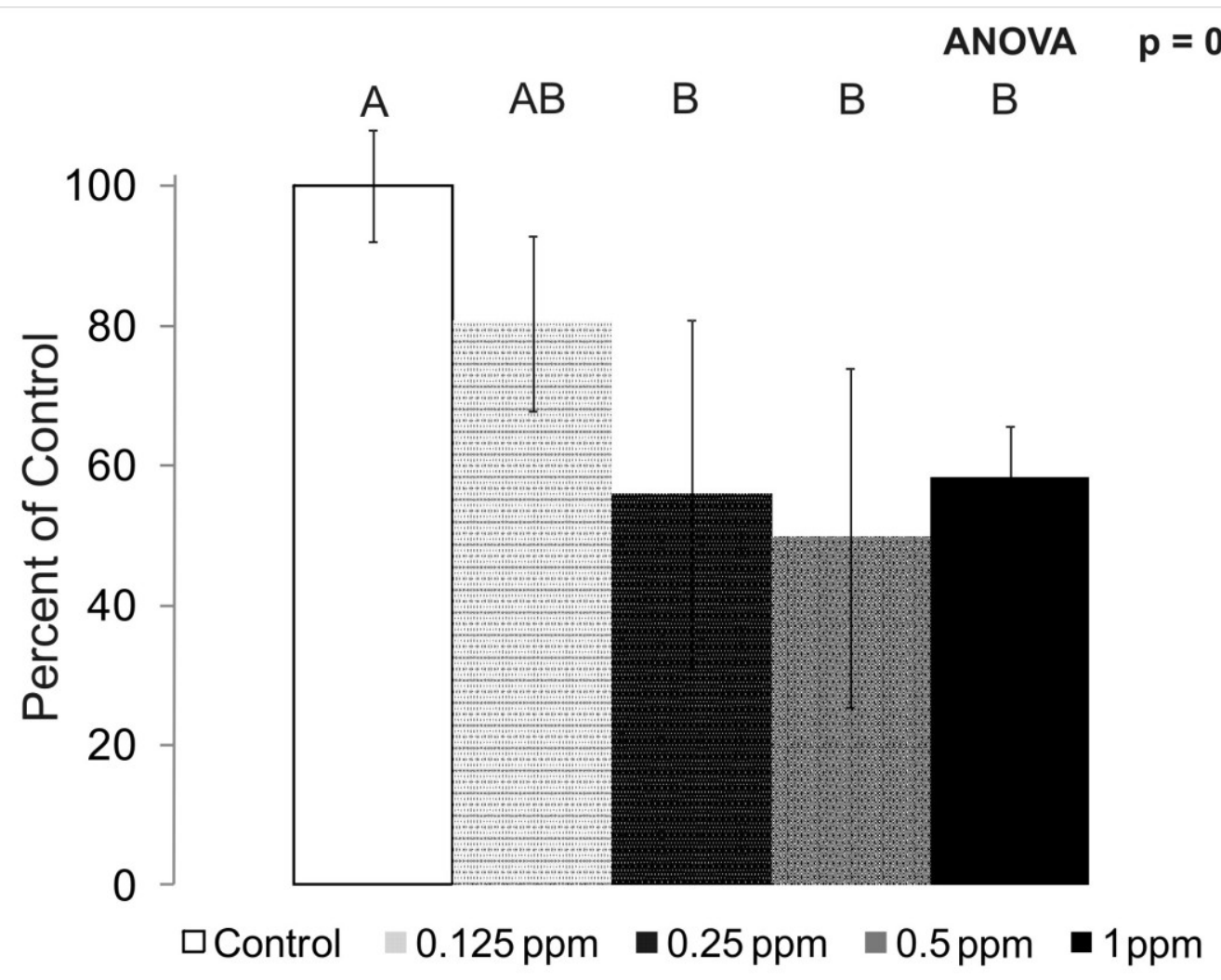

Fig. 14. Daphnia magna reproductive means (as percent control) \pm 1 standard deviation exposed to multi-walled carbon nanotubes for 21 days. 


\section{ANOVA $p<0.0001$}

A

B

A

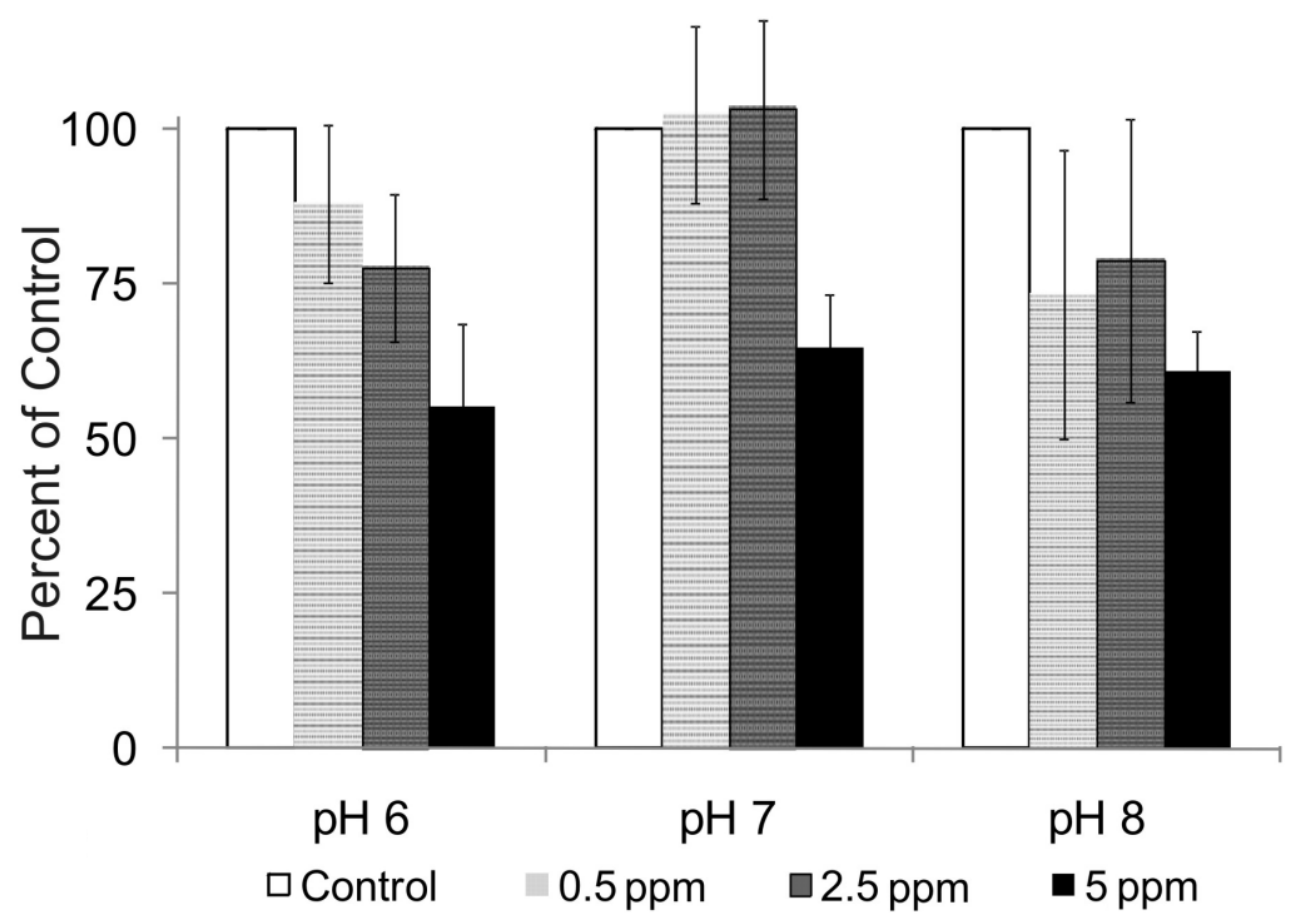

Fig. 15. Ceriodaphnia dubia reproductive means (as percent control) \pm 1 standard deviation exposed to multi-walled carbon nanotubes at three $\mathrm{pH}$ adjustments for 7 days. 
TABLE 7. Reproductive means (as percent control) \pm 1 standard deviation.

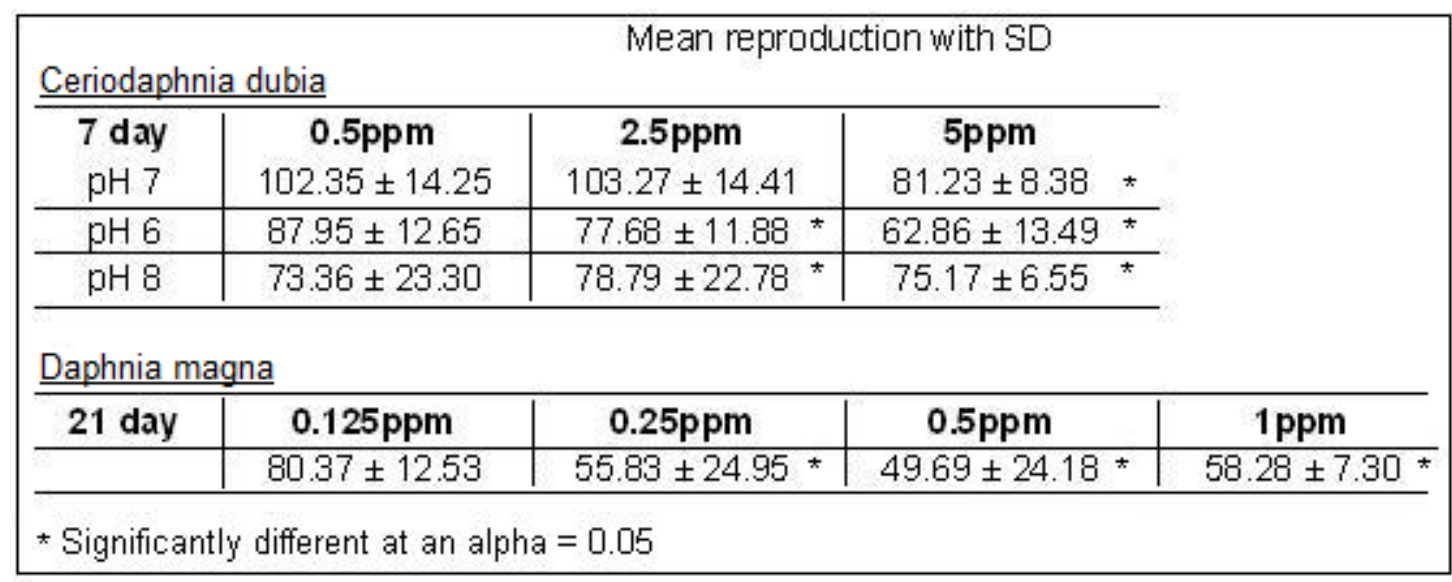




\section{DISCUSSION}

\section{Survival}

Significant mortality was not found in exposures up to $10 \mathrm{ppm}$ multi-walled carbon nanotube (MWNT). Kennedy et al. (2009) did not report acute mortality in Ceriodaphnia dubia with non-functionalized MWNTs until 16ppm (Table 1). The highest exposure used in acute toxicity assays (10ppm) may not have been concentrated enough for significant toxicity to be observed. In a cladoceran lifetable suspended solids toxicity test, Kirk and Gilbert (1991) did not report significant juvenile $\underline{\mathrm{C}}$. dubia mortality at $10 \mathrm{ppm}$ suspended clay, but total juvenile mortality at 50ppm suspended clay, but the same 50ppm exposure concentration caused $80 \%$ morality in juvenile Daphnia ambigua and $44 \%$ in Daphnia pulex. The lower exposure, 10ppm suspended clay, did not induce significant mortality among any of the three cladocerans tested (Kirk and Gilbert 1991).

\section{Growth}

Significant reduction in growth as compared to controls was observed following exposures to $5 \mathrm{ppm}$ and 10ppm MWNT. This is in agreement with preliminary data collected by Taylor et al. (2007). The growth deficit may be due to an inhibition of nutrient uptake. It is established in the literature that daphnia readily ingest carbon nanotube (CNT) aggregates (Roberts et al. 2007, Kennedy et al. 2009, Figure 16). These aggregates likely displace digestible material in the daphnid gut tract and thus change the ratio of energy expended in feeding to 
energy derived by the organism. This energy deficit in turn changes the partitioning of energy for activity, growth and reproduction (Kirk 1991).

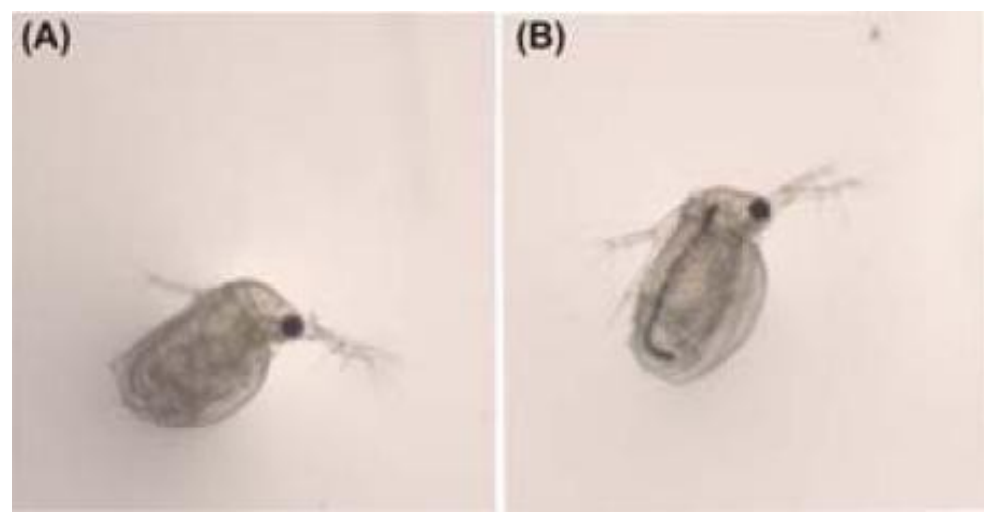

Fig. 16. Cerodaphnia dubia, (A), in natural organic matter solution without multiwalled carbon nanotubes, and (B), after exposure to multi-walled carbon nanotubes.

This mode of inhibition has been established for other inorganic suspensions, such as clays, with daphnia (Arruda et al. 1983, McCabe and O'Brien 1982, Hart 1986, Kirk 1991). The actual mechanism at work could be reduction in algal ingestion per unit volume, reductions in the assimilation of ingested algae, or a combination of the two. Kirk and Gilbert (1990) and Kirk (1991) conducted long-term feeding experiments with a variety of cladocerans to determine population effects of feeding inhibition resulting from exposure to suspended solids. Kirk (1991) reported that 50ppm suspended solids greater than $2 \mu \mathrm{m}$ in size reduce cladoceran algae intake by 13-83\%. Kirk (1991) stated that greater reductions in algal ingestion rate will result in less energy and 
nutrients being available for the individual's use. Reduced energy and nutrients result in reduced body size.

\section{Effect of $\mathrm{pH}$ on Growth and Survival}

Mean aggregate size was altered by adjustment in $\mathrm{pH}$ (Table 4). Dynamic light scattering (DLS) data showed modest variation in hydrodynamic size. However, the scanning electron microscope (SEM) imaging showed aggregates with means an order of magnitude larger than predicted by DLS measurements. This may be due to a limitation of DLS measurements. Particle size measurement is limited by the wavelength of the laser beam on the DLS unit, in this case $633 \mathrm{~nm}$. Once aggregates surpass this wavelength (particles $>600 \mathrm{~nm}$ in diameter), the DLS measures the size of the sub-units of the actual aggregate (D'Souza personal communication 2010). Thus, for the remainder of this thesis, aggregate measurements referred to are those measured by SEM.

Zeta potential measurements indicate there was $\mathrm{pH}$-dependent variation in surface charge which alters the electrostatic repulsion in the natural organic matter (NOM) coating the MWNTs. This changes the folding of the NOM molecules which determines the amount which can fit onto the MVNT surface. The difference in the amount of NOM coating changes the stability of the suspension as the NOM acts like a surfactant in stabilizing an otherwise very hydrophobic molecule in aqueous media. The range of zeta potential change achieved, although small, (Table 4) was enough to alter aggregate size as measured by SEM. A change of $\pm 10 \mathrm{mV}$ would be the most expected from the 
$\mathrm{pH}$ range tested as reported in the literature (Lin et al. 2009, Figure 17). This is similar to what was measured in my samples.

However, the data demonstrate that the changes in mean aggregate size did not affect growth or survival. The lack of effect of aggregate size on toxicity likely means that, while $\mathrm{pH}$ affected nanomaterial behavior, the differences in aggregate size were not enough to cause differences in the biological response. D. magna are able to ingest particles ranging in size from $0.1 \mu \mathrm{m}$ to $>30 \mu \mathrm{m}$ (Porter et al. 1983). The SEM data indicate the MWNTs in this experiment changed $+/-3.5 \mu \mathrm{m}$ with $\mathrm{pH}$ adjustment. Thus, this relatively small change in particle size compared to the range of ingestible particle sizes may be negligible for the organism. Perhaps a more broad range of $\mathrm{pH}$ adjustment would alter aggregate size sufficiently, but such $\mathrm{pH}$ extremes themselves may have an effect on the test organisms. 


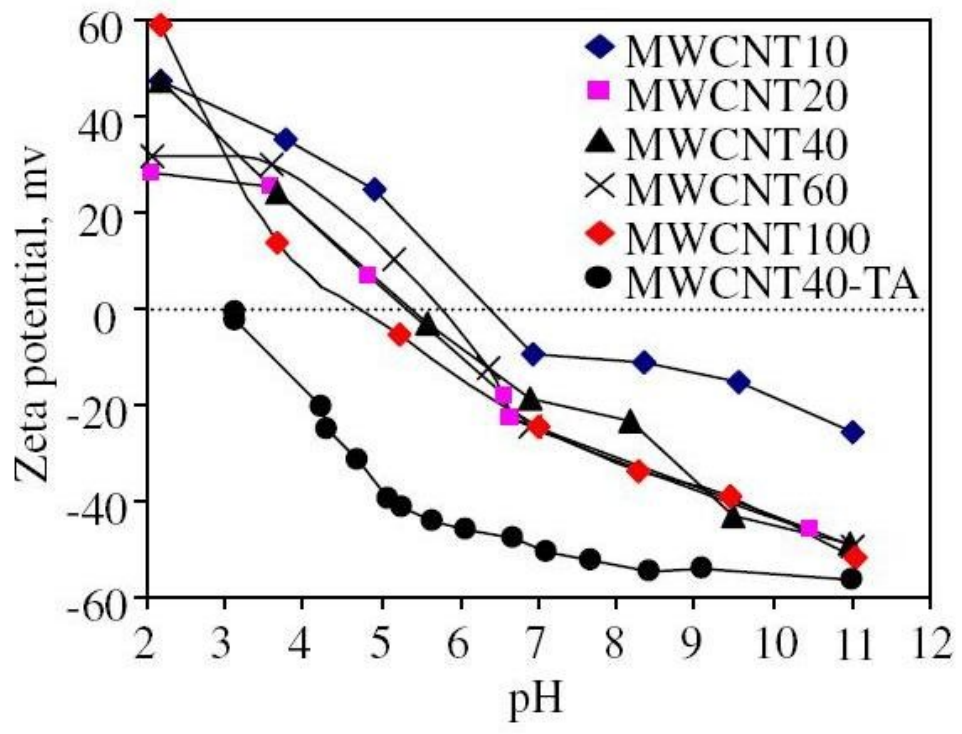

Fig. 17. Zeta potentials of multi-walled carbon nanotubes in deionized water and multi-walled nanotubes outer diameter of 40 nanometers in $20 \mathrm{ppm}$ tannic acid solution at a range of $\mathrm{pHs}$ (Figure from Lin et al. 2009).

\section{Reproduction}

There was a deleterious effect of exposure to MWNTs on daphnid reproduction. There is no published literature on the reproductive effects of carbonaceous nanoparticles on cladocerans. However, in lifetable and population growth experiments, Kirk and Gilbert (1990) demonstrated declines in the populations of four cladoceran species (Bosmina, Ceriodaphnia, and two Daphnia) exposed to suspended clay particles $(<2 \mu \mathrm{m})$. They reported decreased population growth rates in the presence of suspended solids ranging between 1 $\mu \mathrm{m}$ and $3 \mu \mathrm{m}$, and stated that particles of that size range in concentrations greater than 50ppm would likely suppress cladoceran reproduction rates (Kirk 
and Gilbert 1990). Suspended clay has been reported to reduce the assimilation efficiency of ingested algal food (Arruda et al. 1983). Arruda et al. (1983)

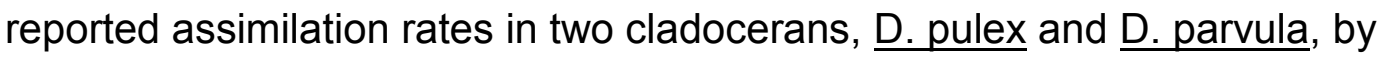
approximately $20 \%$ when exposed to $10 \mathrm{ppm}$ suspended clay, and reduction approximating $85 \%$ at $100 p p m$ suspended clay. If suspended MWNTs behave similarly in cladocerans once ingested the mechanism of reproductive depression could be twofold; feeding inhibition combined with reduction of ingested nutrient assimilation.

Based on reproductive endpoints, Daphnia magna were more sensitive to

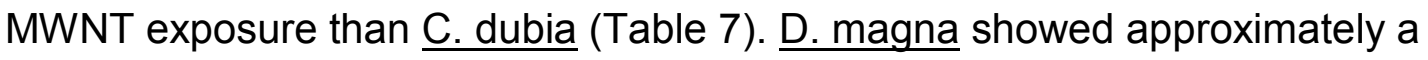

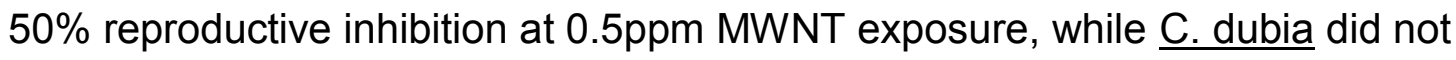
show significant reproductive inhibition at the same exposure concentration and $\mathrm{pH}$. This could be explained by differences between the test organisms. Lynch (1978) reported that Ceriodaphnia still exhibited high growth rates in periods of low food compared to Daphnia pulex sharing the same diet. Porter et al. (1983)

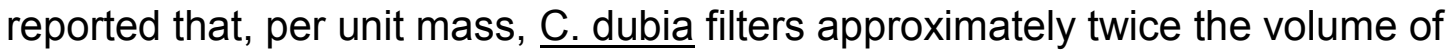

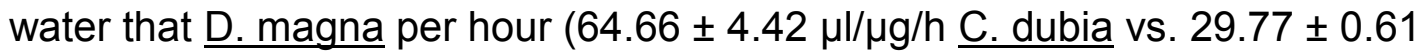

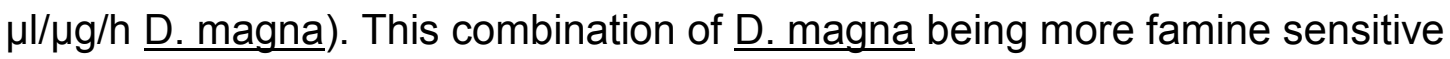

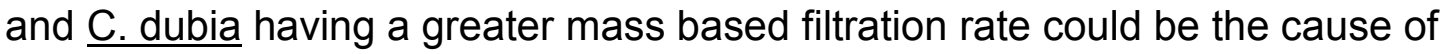
the difference in reproductive means between the two test organisms 
There was no interactive effect of $\mathrm{pH}$ and MWNT concentration on reproduction. As discussed previously, the relatively small differences $\mathrm{pH}$ had on particle size were not significant for the organism.

\section{Conclusions}

MWNTs affected grazing zooplankton growth and reproduction at the tested exposure concentrations. The suspected mode of action of this toxicity is feeding inhibition, leading to a deficit of nutrient intake. Variation of $\mathrm{pH}$ did not significantly alter observed toxicity in acute or chronic tests despite minor alterations in aggregate size.

This investigation has shown that MWNTs can interact with NOM to form stable suspensions which result in toxicity. With current knowledge, there is no easy estimate of an environmentally relevant exposure concentration thus determination of potential risk posed by MWNTs to aquatic ecosystems is difficult. However, MWNTs are an emergent contaminant as both applications and manufacture continue to increase. It is the conclusion of this investigation that MWNTs exhibit little potential for acute toxicity to grazing zooplankton but chronic toxicity could present concerns.

\section{Future Directions \\ Feeding Inhibition}

The next step in this research should be to test the suspected mode of observed toxicity. Provided that it is qualified as being a feeding inhibition the further advancement would be developing an assay to quantify feeding inhibition. 
An experiment similar to the uptake assays was reported by Petersen et al. (2009), using radiolabeled tubes and perhaps radiolabeled algae. This would allow a dose-response curve relating exposure concentration to the amount of interference in nutrient uptake. This would facilitate the creation of energetics models. Such models could be incorporated into risk assessments of nanomaterials.

\section{Comparative Toxicity}

Toxicity of MWNTs as varied by MWNT dimensions is poorly understood. The size of aggregates, rate of aggregate formation, and the stability of suspension as varied by the number of concentric tubes and overall length is poorly understood. Changes in the dimension of MWNTs have been shown in the literature to alter some forms of chemical behavior (Chen 2007). MWNTs released into the environment as a part of waste streams will not be uniform tubes of identical measure.

Functionalization of nanomaterials and MWNTs in particular has been shown to alter chemical behavior and in CNTs, their toxicity by orders of magnitude (Kenndey et al. 2009). Studies of how suspension in freshwater and other waters changes surface chemistry of already functionalized MWNTs are needed. Futhermore, there is a lack of basic toxicity data on identical MWNTs with different surface functionalizations. Already published studies (Kennedy et al. 2009) show that hydroxylated or pristine MWNTs are acutely toxic to daphnids in concentrations tens of parts per million greater than amine or alkyl 
functionalized tubes of the same dimensional characteristics (Table 1). Changes in surface chemistry as exposed to the conditions found in surface waters are critical to further understanding of MWNT aquatic toxicity as well as risk assessment of carbon nanomaterials as a group.

\section{$\underline{\text { Trophic Transfer }}$}

Preliminary tests have shown MWNTs in the digestive tracts of fish (Danio rerio) after ingestion of daphnia exposed to MWNTs without time for the daphnia to depurate. The fish were never placed into water with suspended MWNT aggregates, exposure was dietary. This leads to the question; could the presence of MWNTs impede nutrient uptake by the fish, leading to a similar chronically toxic effect in the next trophic level?

\section{Multi-walled Nanotube Cycling}

As a nanomaterial, MWNTs do not strictly follow the behavior of a normal molecule or of a normal bulk material. Thus predictions on how MWNTs should partition between sediment and pelagic suspension needs to be empirically tested. Complex substrates and biotic activity could interact to move MWNTs out of suspension and into sediment even in solutions with adequate NOM concentrations. Conversely, biotic activity, such as benthic macroinvertebrates' feeding and burrowing activity, could force a certain amount of MWNTs to remain in the pelagic zone. Careful study of likely scenarios with biotic interactions as a component is crucial for future risk assessment of MWNTs in aquatic environments. 


\section{REFERENCES}

Ajayan, P. M. 1999. Nanotubes from carbon. Chemical Review 99(7):1787-1800.

Avouris, P., Z. Chen, and V. Perebeinos. 2007. Carbon-based electronics. Nature Nanotechnology 2(10):605-615.

Bauer, C., J. Buchgeister, R. Hischier, W. R. Poganietz, L. Schebek, and J. Warsen. 2008. Towards a framework for life cycle thinking in the assessment of nanotechnology. Journal of Cleaner Production 16(8-9): 910-926.

Carpenter, S. R., J. J. Cole, J. R. Hodgson, J. F. Kitchell, M. L. Pace, D. Bade, K. L. Cottingham, T. E. Essington, J. N. Houser, and D. E. Schindler. 2001. Trophic cascades, nutrients, and lake productivity: whole-lake experiments. Ecological Monographs 71(2):163-186.

Carpenter, S. R., J. F. Kitchell, and J. R. Hodgson. 1985. Cascading trophic interactions and lake productivity. Bioscience 35(10):634-639.

Chappell, M. A., A. J. George, K. M. Dontsova, B. E. Porter, C. L. Price, P. Zhou, E. Morikawa, A. J. Kennedy, and J. A. Steevens. 2009. Surfactive stabilization of multi-walled carbon nanotube dispersions with dissolved humic substances. Environmental Pollution 157(4):1081-1087.

Chen, W., L. Duan, and D. Zhu. 2007. Adsorption of polar and nonpolar organic chemicals to carbon nanotubes. Environmental Science \& Technology 41(24):8295-8300.

Cheng, C., K. H. Müller, K. K. K. Koziol, J. N. Skepper, P. A. Midgley, M. E. Welland, and A. E. Porter. 2009. Toxicity and imaging of multi-walled carbon nanotubes in human macrophage cells. Biomaterials 30(25): 4152-4160.

Cheng, H., and J. Cheng. 2005. The aggregation of single-walled carbon nanotubes in fresh water and sea water. Off J Soc Toxicol 84(S1):9.

Cheng, J., C. M. Chan, L. M. Veca, W. L. Poon, P. K. Chan, L. Qu, Y. P. Sun, and S. H. Cheng. 2009. Acute and long-term effects after single loading of functionalized multi-walled carbon nanotubes into zebrafish (Danio rerio). Toxicology and Applied Pharmacology 235(2):216-225. 
Datsyuk, V., P. Landois, J. Fitremann, A. Peigney, A. M. Galibert, B. Soula, and E. Flahaut. 2009. Double-walled carbon nanotube dispersion via surfactant substitution. Journal of Materials Chemistry 19(18):2729-2736.

Derycke, V., S. Auvray, J. Borghetti, C. L. Chung, R. Lefèvre, A. Lopez-Bezanilla, K. Nguyen, G. Robert, G. Schmidt, and C. Anghel. 2009. Carbon nanotube chemistry and assembly for electronic devices. Comptes rendus-Physique 10(4):330-347.

Derycke, V., R. Martel, J. Appenzeller, and P. Avouris. 2001. Carbon nanotube inter-and intramolecular logic gates. Nano Letters 1(9):453-456.

Duesberg, G. S., J. Muster, V. Krstic, M. Burghard, and S. Roth. 1998. Chromatographic size separation of single-wall carbon nanotubes. Applied Physics A: Materials Science \& Processing 67(1):117-119.

Esquivel, E. V., and L. E. Murr. 2004. A TEM analysis of nanoparticulates in a polar ice core. Materials Characterization 52(1):15-25.

Foldvari, M., and M. Bagonluri. 2008. Carbon nanotubes as functional excipients for nanomedicines: I. pharmaceutical properties. Nanomedicine: Nanotechnology, Biology, and Medicine 4(3):173-182.

Ghosh, S., H. Mashayekhi, B. Pan, P. Bhowmik, and B. Xing. 2008. Colloidal behavior of aluminum oxide nanoparticles as affected by $\mathrm{pH}$ and natural organic matter. Langmuir 24(21):12385-12391.

Greller, W., and H. Mueller. 1981. The filteration apparatus of cladocera filter mesh sizes and their implications on food selectivity. Oecologia 49(3): 316-321.

Grubek-Jaworska, H., P. Nejman, K. Czumiska, T. Przybyowski, A. Huczko, H. Lange, M. Bystrzejewski, P. Baranowski, and R. Chazan. 2006. Preliminary results on the pathogenic effects of intratracheal exposure to one-dimensional nanocarbons. Carbon 44(6):1057-1063.

Helland, A., and H. Kastenholz. 2008. Development of nanotechnology in light of sustainability. Journal of Cleaner Production 16(8-9):885-888.

Helland, A., P. Wick, A. Koehler, K. Schmid, and C. Som. 2008. Reviewing the environmental and human health knowledge base of carbon nanotubes. Ciência \& Saúde Coletiva 13:441-452.

Heng-Yi, Guo. 2006. Cation-controlled aqueous dispersions of alginicacid-wrapped multi-walled carbon nanotubes. Small 2(7):874-878. 
Henry, T. B., F. M. Menn, J. T. Fleming, J. Wilgus, R. N. Compton, and G. S. Sayler. 2007. Attributing effects of aqueous $\mathrm{C} 60$ nano-aggregates to tetrahydrofuran decomposition products in larval zebrafish by assessment of gene expression. Environmental Health Perspectives 115(7):1059.

Hong, S., and M. Elimelech. 1997. Chemical and physical aspects of natural organic matter (NOM) fouling of nanofiltration membranes. Journal of Membrane Science 132(2):159-181.

Huczko, A., H. Lange, E. Calko, H. Grubek-Jaworska, and P. Droszcz. 2001. Physiological testing of carbon nanotubes: Are they asbestos-like? Fullerene Science and Technology 9(2):251-254.

Hyung, H., J. D. Fortner, J. B. Hughes, and J. H. Kim. 2007. Natural organic matter stabilizes carbon nanotubes in the aqueous phase. Environmental Science \& Technology 41(1):179.

Hyung, H., and J. H. Kim. 2008. Natural organic matter (NOM) adsorption to multi-walled carbon nanotubes: Effect of NOM characteristics and water quality parameters. Environmental Science and Technology 42(12): 4416-4421.

lijima, S. 1991. Helical microtubules of graphitic carbon. Nature 354(6348):56-58.

Itkis, M. E., S. Niyogi, M. E. Meng, M. A. Hamon, H. Hu, and R. C. Haddon. 2002. Spectroscopic study of the Fermi level electronic structure of single-walled carbon nanotubes. Nano Letters 2(2):155-159.

Karajanagi, S. S., H. Yang, P. Asuri, E. Sellitto, J. S. Dordick, and R. S. Kane. 2006. Protein-assisted solubilization of single-walled carbon nanotubes. Langmuir 22(4):1392-1395.

Kennedy, A. J., J. C. Gunter, M. A. Chappell, J. D. Goss, M. S. Hull, R. A. Kirgan, and J. A. Steevens. 2009. Influence of nanotube preparation in aquatic bioassays. Environmental Toxicology and Chemistry 28(9):1930-1938.

Kennedy, A. J., M. S. Hull, J. A. Steevens, K. M. Dontsova, M. A. Chappell, J. C. Gunter, and C. A. Weiss Jr. 2008. Factors influencing the partitioning and toxicity of nanotubes in the aquatic environment. Environmental Toxicology and Chemistry 27(9):1932-1941.

Kim, K. T., A. J. Edgington, S. J. Klaine, J. W. Cho, and S. D. Kim. 2009. Influence of multi-walled carbon nanotubes dispersed in natural organic matter on speciation and bioavailability of copper. Environmental Science and Technology 43(23):8979-8984. 
Kirk, K. L. 1990. Suspended clay reduces daphnia feeding rate. Freshwater Biology 25(2):357-365.

Kirk, K. L. 1991. Inorganic particles alter competition in grazing plankton: the role of selective feeding. Ecology 72(3):915-923.

Kirk, K. L. 1992. Effects of suspended clay on daphnia body growth and fitness. Freshwater Biology 28(1):103-109.

Kirk, K.L., and J. J. Gilbert. 1990. Suspended clay and the population dynamics of planktonic rotifers and cladocerans. Ecology 71(5):1741-1755.

Klaine, S. J., P. J. J. Alvarez, G. E. Batley, T. F. Fernandes, R. D. Handy, D. Y. Lyon, S. Mahendra, M. J. McLaughlin, and J. R. Lead. 2008. Nanomaterials in the environment: Behavior, fate, bioavailability, and effects. Environmental Toxicology and Chemistry 27(9):1825-1851.

Lam, C., J. T. James, R. McCluskey, S. Arepalli, and R. L. Hunter. 2006. A review of carbon nanotube toxicity and assessment of potential occupational and environmental health risks. CRC Critical Reviews in Toxicology 36(3):189-217.

Lin, D., N. Liu, K. Yang, L. Zhu, Y. Xu, and B. Xing. 2009. The effect of ionic strength and $\mathrm{pH}$ on the stability of tannic acid-facilitated carbon nanotube suspensions. Carbon 47(12):2875-2882.

Lin, D., and B. Xing. 2008. Tannic acid adsorbtion and its role for stabilizing carbon nanotube suspensions. Environmental Science and Technology 42(16):5917-5923.

Lovern, S. B., and R. Klaper. 2006. Daphnia magna mortality when exposed to titanium dioxide and fullerene (C60) nanoparticles. Environmental Toxicology and Chemistry 25(4):1132-1137.

Lovern, S. B., J. R. Strickler, and R. Klaper. 2007. Behavioral and physiological changes in Daphnia magna when exposed to nanoparticle suspensions (titanium dioxide, nano- $\mathrm{C} 60$, and $\mathrm{C} 6 \mathrm{OH} \mathrm{HC} 7 \mathrm{OH}$ ). Environmental Science and Technology 41(12):4465-4470.

Lynch, M. 1978. Complex interactions between natural coexploiters - Daphnia and Ceriodaphnia. Ecology 59(3):552-564.

Lynch, M. 1979. Predation, competiton, and zooplankton community structure: An experimental study. American Society of Limnology and Oceanography 24:253-272. 
Maynard, A. D., P. A. Baron, M. Foley, A. A. Shvedova, E. R. Kisin, and V. Castranova. 2004. Exposure to carbon nanotube material: Aerosol release during the handling of unrefined single-walled carbon nanotube materials. Journal of Toxicology and Environmental Health 67:87-107.

Maynard, A. D., B. K. Ku, M. Emery, M. Stolzenburg, and P. H. McMurry. 2007. Measuring particle size-dependent physicochemical structure in airborne single walled carbon nanotube agglomerates. Journal of Nanoparticle Research 9(1):85-92.

McMahon, J. W., and F. H. Rigler. 1965. feeding rate of Daphnia magna Straus in different foods labled with radioactive phosphorus. Limnol Oceaonographer 10:105-113.

Monteiro-Riviere, N. A., and A. O. Inman. 2006. Challenges for assessing carbon nanomaterial toxicity to the skin. Carbon 44(6):1070-1078.

Monteiro-Riviere, N. A., R. J. Nemanich, A. O. Inman, Y. Y. Wang, and J. E. Riviere. 2005. Multi-walled carbon nanotube interactions with human epidermal keratinocytes. Toxicology Letters 155(3):377-384.

Mueller, N. C., and B. Nowack. 2008. Exposure modeling of engineered nanoparticles in the environment. Environmental Science and Technology 42(12):4447-4453.

Murr, L. E., J. J. Bang, E. V. Esquivel, P. A. Guerrero, and D. A. Lopez. 2004. Carbon nanotubes, nanocrystal forms, and complex nanoparticle aggregates in common fuel-gas combustion sources and the ambient air. Journal of Nanoparticle Research 6(2):241-251.

Murr, L. E., K. M. Garza, K. F. Soto, A. Carrasco, T. G. Powell, D. A. Ramirez, P. A. Guerrero, D. A. Lopez, and J. Venzor III. 2005. Cytotoxicity assessment of some carbon nanotubes and related carbon nanoparticle aggregates and the implications for anthropogenic carbon nanotube aggregates in the environment. International Journal of Environmental Research and Public Health 2(1):31-42.

Naeemi, A., R. Sarvari, and J. D. Meindl. 2005. Performance comparison between carbon nanotube and copper interconnects for GSI. IEEE Electronic Device Letters 26:84-86.

Nel, A., T. Xia, L. Madler, and N. Li. 2006. Toxic potential of materials at the nanolevel. Science 311(5761):622.

Oberdörster, E. 2004. Manufactured nanomaterials (fullerenes, C60) induce oxidative stress in the brain of juvenile largemouth bass. Environmental Health Perspectives 112(10):1058. 
Oberdörster, G., E. Oberdörster, and J. Oberdörster. 2005. Nanotoxicology: An emerging discipline evolving from studies of ultrafine particles. Environmental Health Perspectives 113(7):823.

Ouyang, M., J. L. Huang, C. L. Cheung, and C. M. Lieber. 2001. Energy gaps in "metallic" single-walled carbon nanotubes. Science 292(5517):702.

Petersen, E. J., J. Akkanen, J. V. Kukkonen, and W. J. Weber Jr. 2009. Biological uptake and depuration of carbon nanotubes by Daphnia magna. Environmental Science and Technology 43(8):2969.

Pulskamp, K., S. Diabaté, and H. F. Krug. 2007. Carbon nanotubes show no sign of acute toxicity but induce intracellular reactive oxygen species in dependence on contaminants. Toxicology Letters 168(1):58-74.

Radushkevich, L. V., and V. M. Lukyanovich. 1952. Ostukture ugleroda, obrazujucegosja pri termiceskom razlozenij okisi ugleroda na zeleznom kontakte. Russian Journal of Physical Chemistry 26:88-95.

Rakov, E. G. 2008. The current status of carbon nanotube and nanofiber production. Nanotechnologies in Russia 3(9):575-580.

Richard, J. 1894. Entomostraces recuillis par M. E. Modiglianai dans le leac Toba (Sumatra). Am. Mus. 34:556-578.

Roberts, A. P., A. S. Mount, B. Seda, J. Souther, R. Qiao, S. Lin, P. C. Ke, A. M. Rao, and S. J. Klaine. 2007. In vivo biomodification of lipid-coated carbon nanotubes by Daphnia magna. Environmental Science and Technology 41(8):3025-3029.

Shvedova, A. A., E. R. Kisin, R. Mercer, A. R. Murray, V. J. Johnson, A. I. Potapovich, Y. Y. Tyurina, O. Gorelik, S. Arepalli, and D. Schwegler-Berry. 2005. Unusual inflammatory and fibrogenic pulmonary responses to single-walled carbon nanotubes in mice. American Journal of PhysiologyLung Cellular and Molecular Physiology 289(5):698.

Simeonova, P. P. 2009. Update on carbon nanotube toxicity. Nanomedicine $4(4): 373-375$.

Smith, C. J., B. J. Shaw, and R. D. Handy. 2007. Toxicity of single walled carbon nanotubes to rainbow trout (Oncorhynchus mykiss): Respiratory toxicity, organ pathologies, and other physiological effects. Aquatic Toxicology 82(2):94-109.

Star, A., D. W. Steuerman, J. R. Heath, and J. F. Stoddart. 2002. Starched carbon nanotubes. Angewandte Chemie (International ed. in English) 41(14):2508. 
Summers, R. S., and P. V. Roberts. 1988. Activated carbon adsorbtion of humic substances II: Size exclusion and electrostatic interactions. Journal of Colloid Interface Science 122:382-397.

Tejral, G., N. R. Panyala, and J. Havel. 2009. Carbon nanotubes: Toxicological impact on human health and environment. Journal of Applied Biomedicine 7(1):1-13.

Templeton, R. C., P. L. Ferguson, K. M. Washburn, W. A. Scrivens, and G. T. Chandler. 2006. Life-cycle effects of single-walled carbon nanotubes (SWNTs) on an estuarine meiobenthic copepod. Environmental Science and Technology 40(23):7387-7393.

Tervonen, T., I. Linkov, J. R. Figueira, J. Steevens, M. Chappell, and M. Merad. 2009. Risk-based classification system of nanomaterials. Journal of Nanoparticle Research 11(4):757-766.

Tu, X., S. Manohar, A. Jagota, and M. Zheng. 2009. DNA sequence motifs for structure-specific recognition and separation of carbon nanotubes. Nature 460(7252):250-253.

Velasco-Santos, C., A. L. Martinez-Hernández, A. Consultchi, R. Rodriguez, and V. M. Castano. 2003. Naturally produced carbon nanotubes. Chemical Physics Letters 373(3-4):272-276.

Warheit, D. B., B. R. Laurence, K. L. Reed, D. H. Roach, G. A. M. Reynolds, and T. R. Webb. 2004. Comparative pulmonary toxicity assessment of single-wall carbon nanotubes in rats. Toxicological Sciences 77(1):117.

Worle-Knirsch, J. M., K. Pulskamp, and H. F. Krug. 2006. Oops they did it again! Carbon nanotubes hoax scientists in viability assays. Nano Letters 6(6): 1261-1268.

Yamabe, T. 1995. Recent development of carbon nanotubes. Synthetic Materials: 1511-1518.

Yang, K., and B. Xing. 2009. Adsorption of fulvic acid by carbon nanotubes from water. Environmental Pollution 157(4):1095-1100.

Zhu, S., E. Oberdörster, and M. L. Haasch. 2006. Toxicity of an engineered nanoparticle (fullerene, C60) in two aquatic species, Daphnia and fathead minnow. Marine Environmental Research 62:5-9. 